\title{
The emergence of the nicotinamide riboside kinases in the regulation of NAD+ metabolism
}

\author{
Rachel S Fletcher and Gareth G Lavery \\ Institute of Metabolism and Systems Research, University of Birmingham, Birmingham, UK \\ Correspondence should be addressed to G G Lavery: g.g.lavery@bham.ac.uk
}

\begin{abstract}
The concept of replenishing or elevating NAD+ availability to combat metabolic disease and ageing is an area of intense research. This has led to a need to define the endogenous regulatory pathways and mechanisms cells and tissues utilise to maximise $\mathrm{NAD}^{+}$availability such that strategies to intervene in the clinical setting are able to be fully realised. This review discusses the importance of different salvage pathways involved in metabolising the vitamin B3 class of NAD+ precursor molecules, with a particular focus on the recently identified nicotinamide riboside kinase pathway at both a tissue-specific and systemic level.
\end{abstract}

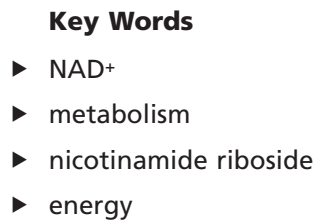

Journal of Molecular Endocrinology (2018) 61, R107-R121

\section{NAD ${ }^{+}$as a redox cofactor and signalling molecule}

The vital role of $\mathrm{NAD}^{+}$in redox metabolism was first described in 1906 by Arthur Harden as being a required cofactor for alcohol fermentation (Harden \& Young 1906). It has since been well established as a redox coenzyme necessary for many redox reactions (EulerChelpin 1966). During these redox events $\mathrm{NAD}^{+}$can be reduced by accepting electrons from donor molecules or, in reverse, NADH can be oxidised to $\mathrm{NAD}^{+}$by donating electrons. This interchange of electrons allows catalysis of reversible transhydrogenase reactions (Warburg \& Christian 1936). Notably, $\mathrm{NAD}^{+}$redox reactions are vital in energy production pathways such as glycolysis, oxidative phosphorylation and fatty acid oxidation. Typically $\mathrm{NAD}^{+}$is predominantly found in its oxidised form with NAD/NADH ratios varying from 10/1 to 700/1 and a total cellular concentration thought to be estimated between $0.3-1.0 \mathrm{mM}$ in mammalian cells (Veech et al. 1972, Casazza \& Veech 1986). Alternatively, $\mathrm{NAD}^{+}$can be phosphorylated to NADP+ by NAD kinase and likewise this also exists in its reduced form NADPH. NADP $(H)$ concentrations are estimated at $10 \%$ of total $\mathrm{NAD}(\mathrm{H})$ levels (Veech et al. 1972, Casazza \& Veech 1986). NADPH acts as an essential reducing agent aiding many anabolic pathways including nucleic acid and lipid biosynthesis (Berger et al. 2004, Tedeschi et al. 2016).

More recently, $\mathrm{NAD}^{+}$has been recognised as an important signalling molecule that is consumed upon the activity of several enzymes including sirtuins (SIRTs), polyADP-ribose polymerases (PARPs) and cyclic ADP-ribose synthases (cADPRSs) (Houtkooper et al. 2010, Dolle et al. 2013). This new found purpose highlighted that $\mathrm{NAD}^{+}$, previously thought of as a stable molecule, is actually in continuous turnover and tightly regulated to maintain metabolic homeostasis. In fact, with approximately 2.5 ATP molecules formed per pair of electrons donated by $\mathrm{NADH}$ in the electron transport chain, and an estimated $80 \mathrm{~kg}$ of ATP turned over by an adult male each day, it is predicted as much as $30 \mathrm{~kg} \mathrm{NADH}$ is generated every day, reinforcing the need for regulated maintenance of $\mathrm{NAD}(\mathrm{H})$ biosynthetic pathways (Kornberg 1991, Walsh et al. 2018). 
SIRTs are important for metabolic energy control, whereby induction of SIRTs results in posttranslational modifications, such as deacetylation of substrate lysine residues, typically in an $\mathrm{NAD}^{+}$-dependent manner (Dali-Youcef et al. 2007, Houtkooper et al. 2012). Following activation, generally at times of energy deficit and concomitant with a rise in $\mathrm{NAD}^{+}$content, SIRT activity (most notably SIRT1 and SIRT3) leads to metabolic adaptation in favour of more efficient ATP generation for example by enhancing mitochondrial content and capacity (Rodgers et al. 2005, Rodgers \& Puigserver 2007, Feige et al. 2008, Canto et al. 2009, 2010, Hirschey et al. 2010, Jing et al. 2011, 2013). In models of SIRT1 and SIRT3 deficiency, metabolic impairments were detected particularly following metabolic challenge (Boily et al. 2008, Hirschey et al. 2010, Xu et al. 2010, Kendrick et al. 2011, Purushotham et al. 2012, Jing et al. 2013). However, muscle and liver-specific models of SIRT3 deficiency did not exhibit a metabolic phenotype despite detectable hyperacetylation of mitochondrial proteins; this was potentially explained by compensation by SIRT3 activity in other tissues or key residues unaffected by hyperacetylation (Fernandez-Marcos et al. 2012). PARPs, on the other hand, belong to the ADPribosyltransferase family and sequentially transfer ADP-ribose from $\mathrm{NAD}^{+}$to proteins, leading to poly ADPribosylation (PARylation) (Decker \& Muller 2002, Luo $\&$ Kraus 2012). Seventeen different PARPs have been identified in mammals and although they have been recognised to have numerous distinct functions the most well-described function of PARP activity is during DNA repair processes (Decker \& Muller 2002). PARP1 is activated by DNA damage and PARylation at these sites leads to recruitment and induction of proteins essential to DNA repair processes (El-Khamisy et al. 2003, Mao et al. 2011, Luo \& Kraus 2012). Although not necessarily $\mathrm{NAD}^{+}$dependent, PARP signalling consumes large quantities of cellular $\mathrm{NAD}^{+}$and exhibits a higher affinity for $\mathrm{NAD}^{+}$than SIRTs therefore prolonged PARP activation may deplete cellular $\mathrm{NAD}^{+}$levels (Charron \& Bonner-Weir 1999, Ha \& Snyder 1999, Kauppinen et al. 2013). Though less well defined, the cADPRSs CD38 and CD157 have also been identified as major NAD ${ }^{+-}$ consuming enzymes (Aksoy et al. 2006, Graeff et al. 2009). They are transmembrane enzymes and play vital roles in several physiological mechanisms including maintaining calcium $\left(\mathrm{Ca}^{2+}\right)$ homeostasis and immune function (De Flora et al. 1998, Graeff et al. 2009).

\section{NAD ${ }^{+}$compartmentalisation}

Distinct subcellular $\mathrm{NAD}(\mathrm{H})$ pools were first proposed due to organelle-specific expression of different $\mathrm{NAD}^{+-}$ generating and -consuming enzymes (VanLinden et al. 2015, Cambronne et al. 2016). Technical advances, most recently in the form and use of fluorescent $\mathrm{NAD}^{+}$ biosensors, have provided support for the idea of compartmentalisation of independent $\mathrm{NAD}^{+}$pools within cells. Nucleic and cytosolic $\mathrm{NAD}^{+}$levels are typically found to be interchangeable with $\mathrm{NAD}^{+}$able to pass freely through nuclear membrane pores. Conversely, the mitochondrial membrane is impermeable to $\mathrm{NAD}^{+}$ and $\mathrm{NADH}$ thus mitochondrial $\mathrm{NAD}^{+}$levels fluctuate independently (Cambronne et al. 2016). A mitochondriaspecific pool of $\mathrm{NAD}^{+}$would seem to enable cells to defend oxidative phosphorylation capacity against transient cytoplasmic/nuclear $\mathrm{NAD}^{+}$depletion (Pittelli et al. 2010). $\mathrm{NAD}^{+}$pool size varies in different tissues, for example, cardiac myocytes have an expectedly higher percentage of mitochondrial $\mathrm{NAD}^{+}$compared to cytosolic yet cell types including astrocytes and hepatocytes have a more substantial cytosolic pool (Alano et al. 2007). These differences would seem to reflect the demand on oxidative capacity and function of the different cells. Despite individual $\mathrm{NAD}^{+}$pools, vital crosstalk exists between compartments. Glyceraldehyde-3-phosphate and malate-aspartate shuttles allow the transfer of electrons from cytosolic NADH into the mitochondria and oxidised $\mathrm{NAD}^{+}$is released into the cytosol. Thus, cytosolic $\mathrm{NAD}^{+}$concentrations are an important determinant of mitochondrial NADH flux; meaning major loss of $\mathrm{NAD}^{+}$, especially in cells predominantly using carbohydrates as a fuel source, would eventually lead to impaired energy production and ultimately cell death (Easlon et al. 2008).

\section{Established NAD+ biosynthesis pathways}

In mammalian cells, a number of $\mathrm{NAD}^{+}$biosynthesis pathways have been established. These pathways can synthesise $\mathrm{NAD}^{+}$de novo from L-tryptophan or from the salvage of vitamin $\mathrm{B} \mathrm{NAD}^{+}$precursors nicotinic acid (NA), nicotinamide (NAM) and nicotinamide riboside (NR) (Houtkooper et al.2010, Dolle et al. 2013) (Fig. 1). The NAD+ biosynthesis pathways can be grouped into two distinct routes described as 'amidated' or 'deamidated' (Mori et al. 2014). De novo synthesis from tryptophan and NA salvage is grouped into the 'deamidated' pathway and shares a 
final rate-limiting amidation enzyme NADsynthase1 (NADSYN) (Preiss \& Handler 1958). Conversely, NAM and NR contain an amide group and therefore follow the 'amidated' route to $\mathrm{NAD}^{+}$(Bieganowski \& Brenner 2004, Tan et al. 2013, Mori et al. 2014) (Fig. 1). The high turnover of $\mathrm{NAD}^{+}$in most cell types means that a major disruption to these biosynthesis pathways could lead to a severe depletion of cellular $\mathrm{NAD}^{+}$levels and, if sustained, ultimately lead to cell death (Hasmann \& Schemainda 2003, Yang et al. 2007).

\section{De novo biosynthesis}

De novo $\mathrm{NAD}^{+}$biosynthesis predominantly begins with the dietary amino acid L-tryptophan. Initially, $\mathrm{N}$-formylkynurenine is generated from tryptophan by the rate-limiting enzyme indoleamine 2,3-dioxygenase or alternatively tryptophan 2,3-dioxygenase. Next, a sequence of four enzymatic reactions convert $\mathrm{N}$-formylknurenine to $\alpha$-amino- $\beta$-carboxymuconate- $\varepsilon$-semialdehyde (ACMS) (Nikiforov et al. 2011). ACMS can either undergo complete oxidation or spontaneous cyclisation to produce quinolinic acid. The conversion of quinolinic acid to nicotinic acid mononucleotide (NAMN) is catalysed by quinolinate phosphoribosyl-transferase and NAMN is subsequently converted to nicotinic acid adenine dinucleotide (NAAD) by the ubiquitously expressed enzyme nicotinamide mononucleotide adenylyltransferase (NMNAT) (Nikiforov et al. 2011). Finally, NAAD is amidated to $\mathrm{NAD}^{+}$in an ATPdependent reaction via glutamine-dependent NADSYN activity (Hara et al. 2003).

\section{Vitamin B3 salvage pathways}

Although de novo biosynthesis is a major route to $\mathrm{NAD}^{+}$in the liver (Bender et al. 1982, Bender \& Olufunwa 1988), the majority of cellular $\mathrm{NAD}^{+}$content in other tissues, and to some degree in the liver, is attributed to salvage pathways which resynthesise $\mathrm{NAD}^{+}$from the vitamin $\mathrm{B} 3$ precursor molecules NA, NAM and NR, also known as niacins (Mukherjee et al. 2017). These precursors share similar chemical structures and can either be absorbed from the diet or found as a consumed $\operatorname{NAD}(\mathrm{P})(\mathrm{H})$ metabolites (Gross et al. 1998, Bieganowski \& Brenner 2004, Khan et al. 2006).

NA can be salvaged to $\mathrm{NAD}^{+}$via the Preiss-Handler pathway; initially NA is converted to NAMN in a reaction is catalysed by NA phosphoribosyltransferase (NAPT) with 5-phospho- $\alpha$-D-ribose-1-diphosphate as its substrate (Preiss \& Handler 1958). The pathway then converges with the de novo biosynthesis pathway; thus, NAMN is converted to NAAD by NMNAT activity and finally to NAD $^{+}$by NADSYN (Preiss \& Handler 1958). Mammalian NADSYN is a homohexameric protein localised to the

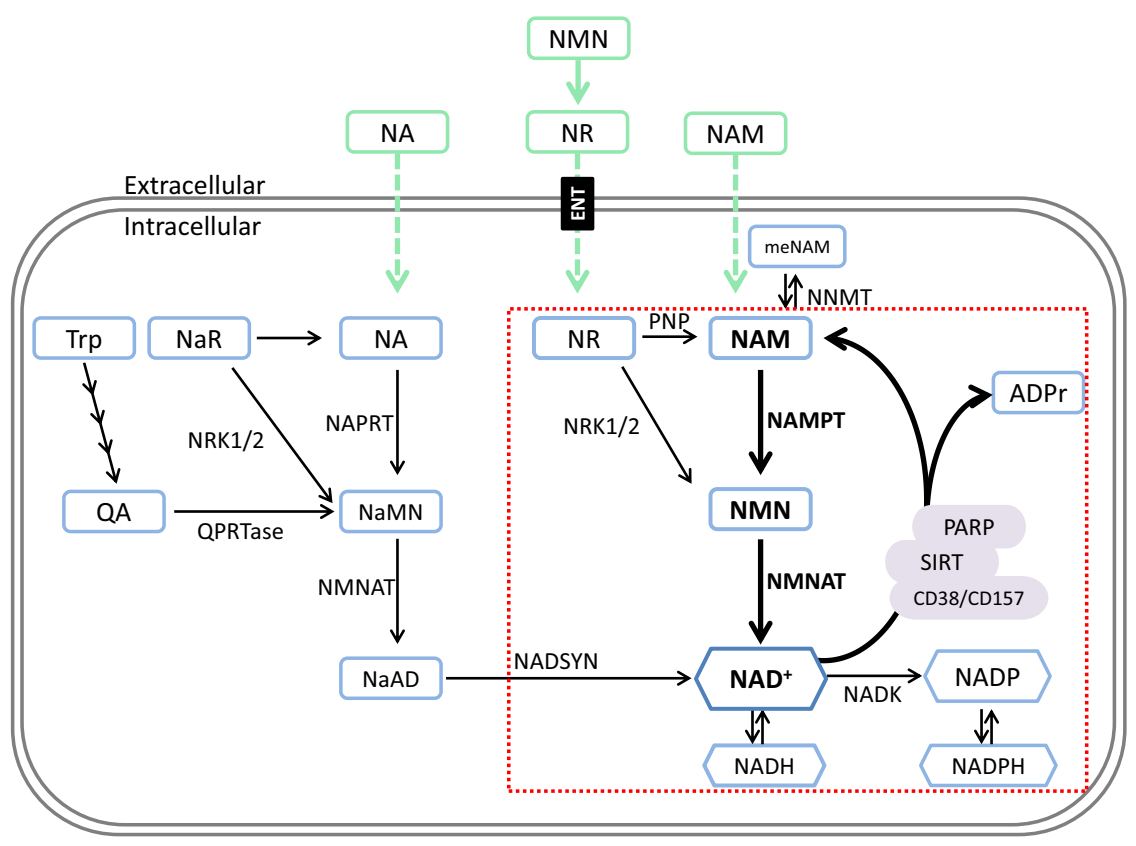

Figure 1

Mammalian NAD+ biosynthesis pathways. An illustration of mammalian NAD+ biosynthesis pathways with exogenous precursor supplementation strategies outlined in green with dashed arrows). NAD+ can be generated from Trp de novo with multiple enzymatic reactions leading to the production of quinolinic acid (QA), which is then converted to nicotinic acid mononucleotide NaMN by QA-phosphoribosyltransferase (QPRTase) and then to nicotinic acid dinucleotide (NaAD) by nicotinamide mononucleotide adenylyltransferase (NMNAT) activity, before the final conversion to NAD+ by NAD synthase (NADSYN). Alternatively NAD+ can be salvaged from precursors and nicotinic acid (NA) nicotinic acid riboside ( $\mathrm{NaR}$ ) by NA phosphoribosyltransferase (NAPRT) nicotinamide riboside kinases (NRK1/2) respectively to NaMN and finally NDA+ by NMNAT. Alternatively, most tissues rely on the amidated routes for NAD+ biosynthesis (outlined in red box). Here, nicotinamide riboside (NR) and nicotinamide (NAM) are salvaged by NRKs and nicotinamide phosphoribosyltransferase (NAMPT) respectively to nicotinamide mononucleotide (NMN) and ultimately converted to NAD+ by NMNAT. http://jme.endocrinology-journals.org https://doi.org/10.1530/JME-18-0085
(C) 2018 The authors Published by Bioscientifica Ltd. Printed in Great Britain

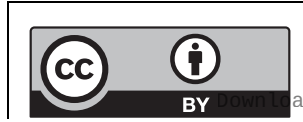

This work is licensed under a Creative Commons Attribution 4.0 Unported License. 
cytosol. Its enzymatic activity requires co-substrates ATP and glutamine to convert NAAD to $\mathrm{NAD}^{+}$and releases AMP, PPi and glutamic acid in the process (Mori et al. 2014). NADSYN is the final rate-limiting step of both the de novo and Preiss-Handler pathway and thus essential for the generation of $\mathrm{NAD}^{+}$via these routes. NADSYN expression and activity has been shown to be both organism and tissue specific. Some microorganisms including Mycobacterium tuberculosis are dependent on NADSYN for $\mathrm{NAD}^{+}$biosynthesis, which consequently makes it a potential antibacterial target, whereas others use alternative pathways for $\mathrm{NAD}^{+}$biosynthesis (Boshoff et al. 2008, De Ingeniis et al. 2012). The rate of NADSYN enzyme activity has been determined in a range of mouse tissues with highest activity levels found in liver and kidney tissue, whereas activity was minimal in brain homogenates and undetectable in lung and skeletal muscle tissues suggesting $\mathrm{NAD}^{+}$biosynthesis via the de novo and Preiss-Handler pathways is limited to certain tissues (Mori et al. 2014).

Alternatively, $\mathrm{NAD}^{+}$can be salvaged from NAM by the nicotinamide phosphoribosyltransferase (NAMPT) pathway (Tan et al. 2013). In this pathway, NAMPT catalyses the first rate-limiting reaction that converts substrates NAM and 5'-phosphoribosyl-1-pyrophosphate (PRPP) to nicotinamide mononucleotide (NMN) in an ATP-dependent reaction. Then, NMNAT activity allows the conversion of $\mathrm{NMN}$ to $\mathrm{NAD}^{+}$(Garten et al.). Importantly, $\mathrm{NAD}^{+}$consumption by SIRT and PARP activity results in the release of NAM as a reaction product; therefore, salvage by NAMPT provides a central cellular $\mathrm{NAD}^{+}$recycling loop. Recycling of $\mathrm{NAD}^{+}$via this pathway is tightly regulated in order to sustain appropriate $\mathrm{NAD}^{+}$homeostasis, with both NAMPT expression and activity shown to be modulated by cellular NAD+ levels and SIRT activity negatively regulated by NAM levels (Bitterman et al. 2002).

NAMPT is a dimeric type II phosphoribosyltransferase that is highly conserved and expressed in nearly all the tissues and cells examined suggesting a vital role for NAMPT activity in normal cell function (Wang et al. 2006, Garten et al. 2015). Initially, it was termed pre-B cell colony-enhancing factor (PBEF) due to its proposed cytokine function (Samal et al. 1994); it was then determined to be a hormonal factor, and renamed visfatin, that supposedly exerted insulin mimetic effects (Fukuhara et al. 2005) that have since been found to be unverified (Harasim et al. 2011). NAMPT is both an intracellular and extracellular protein, the intracellular isoform is predominantly localised to the cytosolic and nucleic fractions (Kitani et al. 2003, Revollo et al. 2007).
Within several cell types NAMPT has been shown as a vital enzyme for maintaining cellular $\mathrm{NAD}^{+}$and energy homeostasis by recycling NAM to NAD+ (Yoon et al. 2015, Frederick et al. 2016, Lin et al. 2016, Agerholm et al. 2018, Nielsen et al. 2018). Pharmacological inhibition of NAMPT using the potent inhibitor FK866 results in $\mathrm{NAD}^{+}$depletion and for cells that predominantly rely on this pathway for $\mathrm{NAD}^{+}$salvage can result in cell death (Hasmann \& Schemainda 2003, Tan et al. 2013). The importance of extracellular NAMPT (eNAMPT) remains unclear. It has been proposed that extracellular activity may be part of a wider pathological process whereby ATP and PRPP - both required for NAM salvage and normally found at low levels in the plasma - are released from dying cells into the circulation and drive enzyme activity (Hara et al. 2011, Garten et al. 2015). In diabetes, an association between eNAMPT and pro-inflammatory responses including the induction of inducible nitric oxide synthase has been reported (Kieswich et al. 2016).

\section{The emergence of the NRK pathway to NAD+}

In healthy cells, the vitamin $\mathrm{B} 3 \mathrm{NAD}^{+}$precursors are essential for replenishing $\mathrm{NAD}^{+}$for the maintenance of appropriate cellular $\mathrm{NAD}^{+}$levels in all compartments supporting energy homeostasis (Bender \& Olufunwa 1988, Bogan \& Brenner 2008, Dolle et al. 2013). The significance of a requirement for vitamin B3 was first delineated in the disease pellagra, a disorder of B3 deficiency, and since then, increasing evidence has shown that a breakdown in the balance of $\mathrm{NAD}^{+}$generation vs $\mathrm{NAD}^{+}$consumption is a common factor in numerous morbidities (Pitche 2005).

In 2004, a new pathway to $\mathrm{NAD}^{+}$synthesis was determined by Charles Brenner following the identification of nicotinamide riboside kinase 1 (Nrk1) in yeast and subsequent human homologs NRK1 and NRK2 (Bieganowski \& Brenner 2004, Tempel et al. 2007). In the initial step of the pathway, NRK activity catalyses the phosphorylation of NR to nicotinamide mononucleotide (NMN) (Tempel et al. 2007), which is subsequently converted to $\mathrm{NAD}^{+}$by NMNAT (Fig. 2) (Bieganowski \& Brenner 2004). Alternatively, NRK activity can phosphorylate nicotinic acid riboside (NaR) to nicotinic acid mononucleotide (NaMN), which is then converted to $\mathrm{NaAD}$ and finally $\mathrm{NAD}^{+}$by NMNAT and NADSYN, respectively (Tempel et al. 2007). The discovery of the NRK enzymes stemmed from previous work that showed NR, as a novel NAD ${ }^{+}$precursor, could extend the lifespan of yeast through the induction of Sir2 in an $\mathrm{NAD}^{+}$-dependent manner (Bieganowski \& Brenner 2004). Since then, the

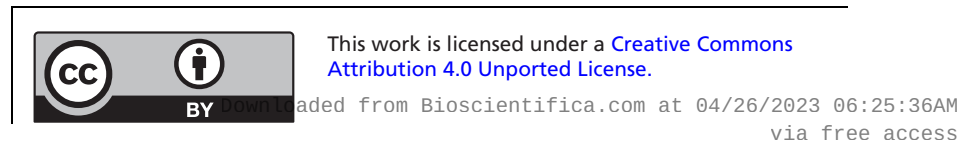




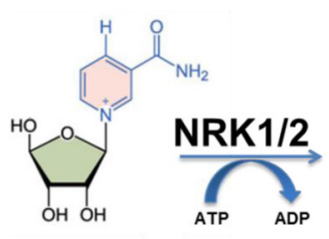

NR

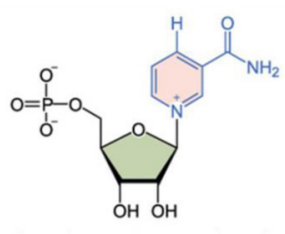

NMN

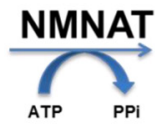

mounting evidence towards the beneficial effects of using $\mathrm{NAD}^{+}$precursors, and in particular, NR and $\mathrm{NMN}$, has led to the emergence of the NRK enzymes as therapeutic targets. Although the NRK enzymes were identified as an alternative salvage pathway to $\mathrm{NAD}^{+}$(Bieganowski \& Brenner 2004), investigations have only recently begun to define the importance of NRK1 and 2 in terms of NAD ${ }^{+}$ metabolism and beyond.

NRK1 and 2 (encoded by Nmrk1 and Nmrk2 genes, respectively) both exhibit a high affinity for NR, yet, their substrate specificity differs (Fig. 1). With ATP as a co-substrate NRK1 has a $K_{\mathrm{M}}$ of $0.088 \mathrm{mM}$ for NR, whereas NRK2 has a $K_{\mathrm{M}}$ of $0.19 \mathrm{mM}$ (Tempel et al. 2007). Furthermore, NRK1 can also use GTP (guanosine triphosphate) as a co-substrate for the phosphorylation of NR yet NRK2 is restricted to ATP (Tempel et al. 2007, Dölle $\&$ Ziegler 2009). The enzyme turnover of NR to NMN with ATP has also been estimated; here, the $K_{\text {cat }}$ was found to be around $0.6 / \mathrm{S}$ for NRK1 and $0.75 / \mathrm{S}$ for NRK2 (Tempel et al. 2007). On the other hand, NRK1 and NRK2 exhibit a similar affinity for $\mathrm{NaR}$ with a $K_{\mathrm{M}}$ of $0.051 \mathrm{mM}$ and $0.063 \mathrm{mM}$, respectively (Fig. 1 and Table 1). Further kinetic studies using a pyruvate kinase/lactate dehydrogenasecoupled enzyme assay confirmed these findings with the $K_{\mathrm{M}}$ of NRK1 and 2 found to be in the micromolar range and NRK1 again exhibiting a higher affinity for NR. Interestingly, here they also showed that NRK2 had a 10-fold higher affinity than NRK1 for uridine; yet, they share a similar affinity for cytidine (Dölle \& Ziegler 2009).

In mammalian tissues, NRK1 is ubiquitously expressed, whereas NRK2 has been shown to be muscle specific with expression more predominant in skeletal muscle compared to cardiac (Fletcher et al., Ratajczak et al . 2016). Initial studies in zebrafish identified that Nrk2b is a vital component for musculoskeletal development. In Nrk2b-deficient zebrafish muscular abnormalities were identified, including irregular laminin polymerisation at myotendinous junctions and abnormally long muscle fibres that have elongated into adjacent myotomes (Goody et al. 2010). These changes were caused by aberrant cell matrix adhesion complex signalling driven

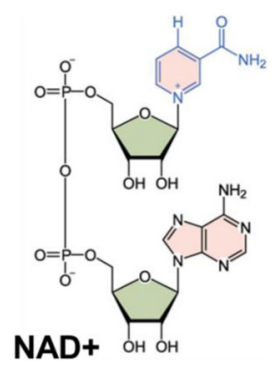

Figure 2

NRK1/2 mediated NAD+ biosynthesis pathway. Nicotinamide riboside (NR) is metabolised by nicotinamide riboside kinase (NRK1/2) to nicotinamide mononucleotide (NMN) and subsequently converted to NAD+ by NMNadenylyltransferase (NMNAT) activity.

by atypical localisation of Paxillin. It is proposed that the Nrk2b homolog is specifically localised to myotendinous junctions to provide a local $\mathrm{NAD}^{+}$supply, and this may potentially explain why the alternative Nrk homologs are unable to compensate. Importantly, this phenotype was rescued following administration of $\mathrm{NAD}^{+}$demonstrating that the effects were $\mathrm{NAD}^{+}$dependent and that $\mathrm{Nrk} 2 \mathrm{~b}$ plays a central role in zebrafish $\mathrm{NAD}^{+}$biosynthesis (Goody et al. 2012).

However, murine NRK1 and NRK2 loss-of-function models do not exhibit any gross phenotypic abnormalities, with steady state $\mathrm{NAD}^{+}$levels unaffected, at least in the tissues that have been examined (liver, skeletal muscle, brown adipose and kidney) (Fletcher et al., Ratajczak et al. 2016). Thus, despite the NRK salvage pathway being highly conserved (Bieganowski \& Brenner 2004), it appears to play a redundant role in basal murine metabolism; with most tissues examined reliant on the NAMPT salvage pathway to maintain $\mathrm{NAD}^{+}$levels (Fletcher et al., Tan et al. 2015, Frederick et al. 2016, Stromsdorfer et al. 2016, Zhang et al. 2017, Agerholm et al. 2018, Nielsen et al. 2018). The differences seen between zebrafish and murine models following loss of NRK function may be attributed to an absence of alternative $\mathrm{NAD}^{+}$biosynthesis pathways in zebrafish skeletal muscle tissue. Although NRK1 and NRK2 do not appear critical in mice for endogenous $\mathrm{NR}$ salvage to $\mathrm{NAD}^{+}$, their activity has been determined essential for the utilisation of exogenous NR and, more surprisingly, NMN. Following supplementation, it is

Table 1 Estimated NRK1 and NRK2 enzyme kinetics and substrate specificity (Tempel et al. 2007).

\begin{tabular}{|c|c|c|c|c|}
\hline Substrate & $\boldsymbol{K}_{\mathbf{M}}(\mathrm{mM})$ & $\boldsymbol{K}_{\text {cat }}(/ \mathrm{S})$ & $\boldsymbol{K}_{\mathrm{cat}} / \boldsymbol{K}_{\mathrm{M}}(/ \mathrm{S} / \mathrm{M})$ & $\begin{array}{l}\text { Substrate } \\
\text { specificity }\end{array}$ \\
\hline \multicolumn{5}{|l|}{ NRK1 } \\
\hline $\mathrm{NR}+\mathrm{ATP}$ & 0.088 & 0.6 & 6800 & ATP, GTP \\
\hline $\mathrm{NR}+\mathrm{GTP}$ & 0.068 & 0.34 & 5000 & \\
\hline $\mathrm{NaR}+\mathrm{ATP}$ & 0.051 & 0.21 & 4100 & \\
\hline \multicolumn{5}{|l|}{ NRK2 } \\
\hline $\mathrm{NR}+\mathrm{ATP}$ & 0.19 & 0.75 & 3900 & ATP \\
\hline $\mathrm{NR}+\mathrm{GTP}$ & 30 & 1.7 & 57 & \\
\hline $\mathrm{NaR}+\mathrm{ATP}$ & 0.063 & 0.34 & 5400 & \\
\hline
\end{tabular}


thought NR is transported into cells via the nicotinamide riboside transporter orthologue of the yeast Nrt1 protein (Belenky et al. 2011).

Without expression of the NRK enzymes in tissues, the NAD+-boosting effects of $\mathrm{NR}$ and $\mathrm{NMN}$ supplementation is blocked, whilst expression of alternative $\mathrm{NAD}^{+}$ biosynthesis enzymes remains comparable to WT mice (Fletcher et al., Ratajczak et al. 2016). In addition, the $\mathrm{NAD}^{+}$boosting effect of NR and NMN supplementation following NAMPT inhibition by FK866 in muscle and hepatic cells is comparable to that of untreated cells. Interestingly, phosphorylation of NR by NRK1 appears preferred to NRK2 even in skeletal muscle where Nmrk2 is specifically expressed and found at substantially higher mRNA levels than Nmrk1 (Fletcher et al.). This firstly shows the NRK enzymes exclusively metabolise NR, but it also suggests that NMN must be converted to NR to enter the cell and then be re-phosphorylated intracellularly back to NMN (Fletcher et al., Ratajczak et al. 2016). Previous studies have shown that NMN can be dephosphorylated by cytosolic 5'-nucleotidases and thus it has been postulated that NMN is dephosphorylated to NR extracellularly by the cell membrane protein CD73 (also known as ecto-5-nucleotidase) and then imported into the cell (Kulikova et al. 2015).

\section{Organism and tissue NAD+ salvage pathway specificity}

$\mathrm{NAD}^{+}$biosynthesis and salvage enzymes are evolutionarily conserved from bacteria to mammals yet in some organisms certain pathways are preferred (Berger et al. 2004). For example, in mammals, the NAMPT-mediated $\mathrm{NAD}^{+}$biosynthesis pathway is essential for maintaining adequate cellular $\mathrm{NAD}^{+}$levels and complete absence of the Nampt gene is embryonically lethal (Garten et al. 2015, Tan et al. 2015, Zhang et al. 2017). Despite being well conserved in mammals, the NRK enzymes appear nonessential yet some microorganisms rely on NRK activity to salvage $\mathrm{NAD}^{+}$(Fletcher et al., Gazzaniga et al. 2009, Ratajczak et al. 2016). For example, the multifunctional protein NadR is expressed in microorganisms and exhibits both ribosylnicotinamide kinase (RNK) activity to phosphorylate NR or NaR, as well as Nmnat activity for $\mathrm{NAD}^{+}$biosynthesis. In Haemophilus influenzae, NadR activity is essential for growth yet in microorganisms such as Salmonella enterica serovar Typhimurium, NadR activity is present but not vital (Kurnasov et al. 2002).

The relative importance and tissue specificity of the different precursor molecules in $\mathrm{NAD}^{+}$replenishment in vivo is becoming well defined in some tissues but is unclear in others. For example, de novo biosynthesis is thought to be the preferred route for $\mathrm{NAD}^{+}$biosynthesis in the liver (Bender et al. 1982, Bender \& Olufunwa 1988), with hepatocyte $\mathrm{NAD}^{+}$content potentially more resistant to loss of NAMPT function compared to tissues such as muscle and fat (Schuster et al. 2015, Ratajczak et al. 2016). With that said, changes to NAMPT expression in hepatocytes has been shown to alter NAD+ content and induce physiological changes highlighting that the NAMPT salvage pathway still plays an important role in hepatocyte NAD+ biosynthesis (Zhou et al. 2016, Mukherjee et al. 2017, Zhang et al. 2017). In the majority of other tissues investigated to date, it is thought that cellular $\mathrm{NAD}^{+}$is predominantly attributed to $\mathrm{NAD}^{+}$salvage pathways using vitamin $\mathrm{B} 3$ precursors found in the diet or as consumed $\mathrm{NAD}^{+}$metabolites (Mori et al. 2014). In many of these tissues, direct recycling of NAM is believed to be preferred over NA salvage; with only transient increases in $\mathrm{NAD}^{+}$following intraperitoneal injection of NA compared to stable increases following NAM administration (Collins \& Chaykin 1972). This is further supported by evidence showing NADSYN activity, the final rate-limiting enzyme in the NA salvage pathway appears inferior to the final rate-limiting step of the amidated pathways (Mori et al. 2014). In mammalian tissue, NR salvage to $\mathrm{NAD}^{+}$via the NRK enzymes is not essential and appears limited to NR availability with endogenous NR levels seemingly low in tissues yet exogenous delivery of NR appears highly effective in enhancing $\mathrm{NAD}^{+}$directly through NRK activity (Fletcher et al., Ratajczak et al. 2016).

\section{Regulation of the NRK enzymes}

Aside from the requirement for NRK1 and/or NRK2 to enhance cellular $\mathrm{NAD}^{+}$content following exogenous NR or NMN supplementation, recent data suggest NRK2 may play a an important endogenous role in adaptation to metabolic and energy stress. The regulation of NRK2 has been determined in pathophysiological settings and in response to $\mathrm{NAD}^{+}$insufficiency (Fig. 3 - upper panel) (Fletcher et al., Sasaki et al. 2006, Lavery et al. 2008, Aguilar et al. 2015, Xu et al. 2015, Diguet et al. 2017). Following injury to dorsal root ganglion neurons, Nmrk2 was the most upregulated $\mathrm{NAD}^{+}$biosynthetic gene (by over 20-fold), which is surprising considering Nmrk2 expression is typically absent or detected at low levels in central nervous system tissues (Sasaki et al. 2006). In addition, in a mouse model of traumatic lower limb muscle injury, Nmrk2 was again found to be significantly

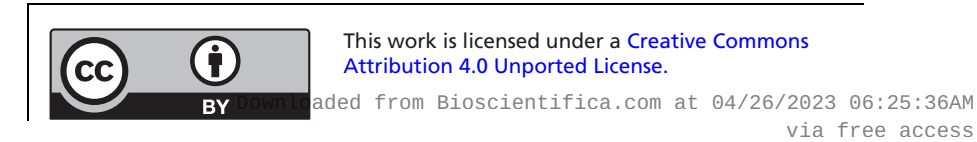


Adaptive NRK expression

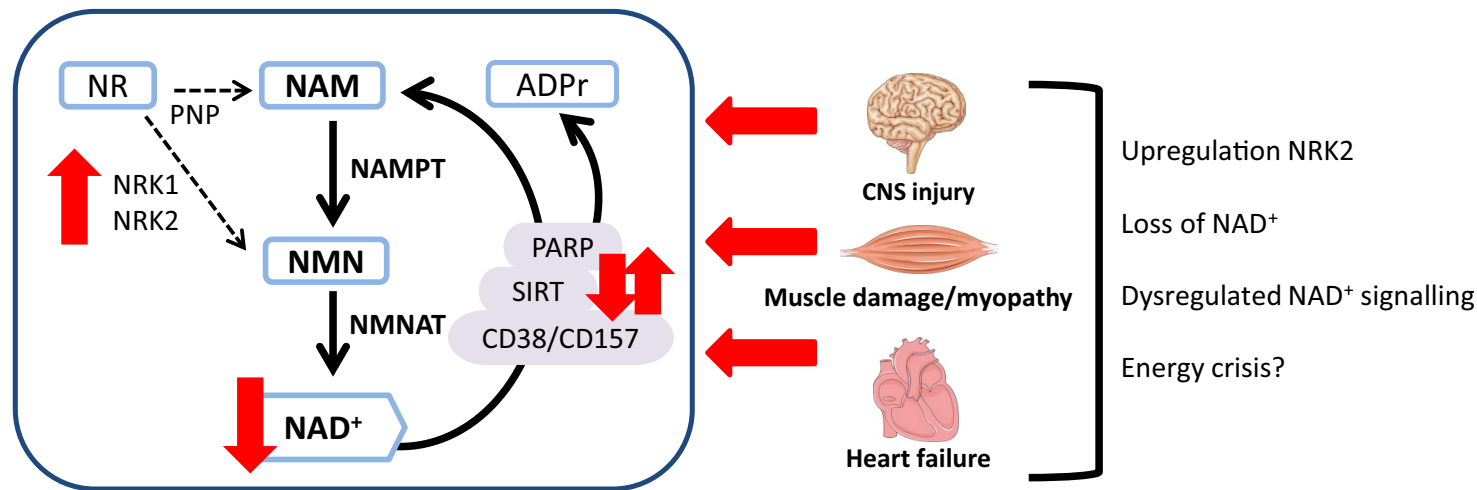

Precursor supplementation

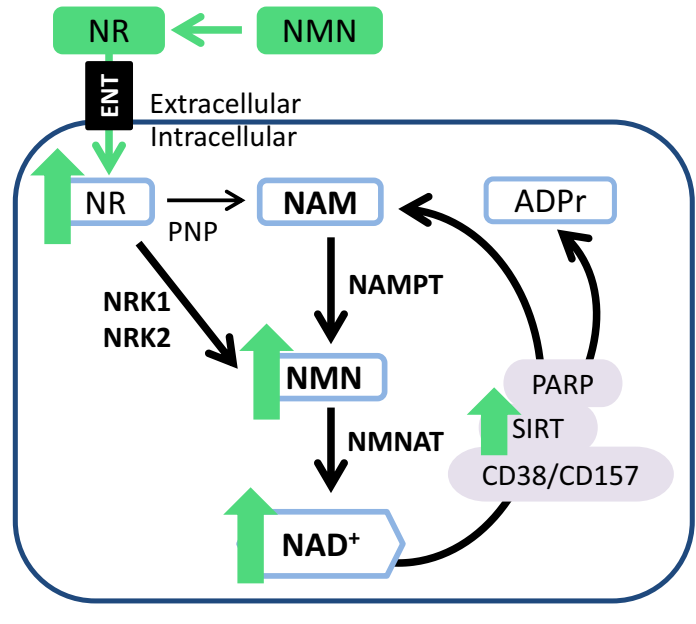

\section{Effects in tissue pathology}

$\downarrow$ Weight gain, $\uparrow$ insulin sensitivity

Stem cell rejuvenation

Stem cells

$\downarrow$ Cognitive degeneration,$\uparrow$ Neurogenesis

CNS

$\uparrow$ mito. content, $\downarrow$ mito. myopathy, $\downarrow$ age related atrophy

Muscle

Improved cardiac function

Heart

$\downarrow$ Hepatic Steatosis, $\uparrow$ glucose tolerance

Figure 3

Proposed NRK expression in disease and potential therapeutic interventions. Adaptive NRK expression (Top) has been identified in numerous pathological scenarios where commonly an induction of NRK2 expression has been seen with loss of NAD+ and altered activity of NAD+-consuming enzymes. Supplementation with NAD+ precursors nicotinamide riboside (NR) and nicotinamide mononucleotide (NMN) (bottom), both requiring NRK activity, can elevate intracellular NAD+ and has been shown to result in many health benefits in numerous rodent models.

upregulated (three-fold) at $24 \mathrm{~h}$ post injury (Aguilar et al. 2015). Mice with a loss of hexose-6-phosphate dehydrogenase (H6PDH) function, an ER-based enzyme required for local NADPH generation, manifest with severe muscle myopathy and on transcriptional analysis Nmrk2 expression was the most dysregulated gene (upregulated by $>60$-fold mRNA level) (Lavery et al. 2008). Furthermore, Nmrk2 mRNA expression was substantially induced (>80-fold) in models of lethal cardiomyopathy (Xu et al. 2015). In this model, administration with NR was able to increase lifespan of these mice by $50 \%$ suggesting that this induction of Nmrk2 in cardiac tissue is to support NAD ${ }^{+}$ generation ( $\mathrm{Xu}$ et al. 2015). The hypothesis of Nmrk2 induction to support NAD+ biosynthesis during injury or potentially extreme energetic stress is further supported by its induction during $\mathrm{NAD}^{+}$depletion. For example, loss of

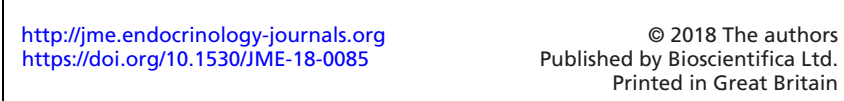

$\mathrm{NAD}^{+}$by pharmacological inhibition of NAMPT also leads to an induction in Nmrk2 expression, which is normalised when $\mathrm{NAD}^{+}$levels are restored with NR supplementation (Fletcher et al.).

More recently, in two murine models of the failing heart that cause dilated cardiomyopathy or cardiac hypertrophy, a significant induction of NRK2 - by 40-fold and 4-fold respectively - was determined (Diguet et al. 2017). Conversely, NAMPT expression was downregulated and $\mathrm{NAD}^{+}$levels were reduced in both models. Similar changes were seen in human failing hearts (Diguet et al. 2017). These findings led to the proposal by Diguet et al. that in $\mathrm{NAD}^{+}$deficiency, NRK2 may be induced to aid $\mathrm{NAD}^{+}$biosynthesis. Circulating NR levels are thought to be low or absent (Trammell et al. 2016a) but importantly upon dietary NR supplementation protective effects to

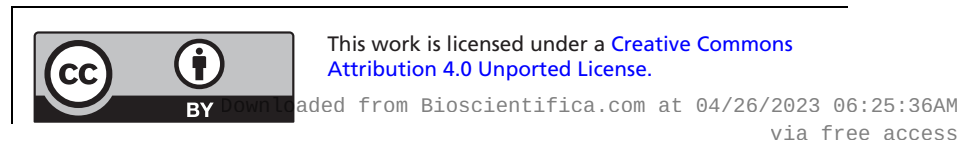


cardiac function were seen (Diguet et al. 2017). They went on to describe the first mechanisms regulating mammalian NRK2 expression. Upregulation of Nmrk2, in response to ATP and $\mathrm{NAD}^{+}$depletion, suggested Nmrk2 is controlled by energy metabolism signalling pathways (Diguet et al. 2017). Supporting this hypothesis, they found that Nmrk2 was regulated during energetic stress in an AMP-kinase and peroxisome proliferator-activated receptor $\alpha(\operatorname{PPAR} \alpha)$ dependent manner in cardiac cells (Diguet et al. 2017).

Intracellular $\mathrm{NAD}^{+}$concentrations, as well as Sirt1 and Nampt gene expression, have been shown in the liver to be regulated by the circadian clock oscillating in a 24-h rhythm (Nakahata et al. 2009). The expression of these genes and $\mathrm{NAD}^{+}$levels are impacted by circadian clock gene loss of function and in reverse pharmacological inhibition of NAMPT and loss of $\mathrm{NAD}^{+}$impacted on circadian gene expression profiles (Nakahata et al. 2009). In addition high-fat diet-fed mouse livers saw remodelling of circadian clock expression and ablation of circadian $\mathrm{NAD}^{+}$, further linking the importance of $\mathrm{NAD}^{+}$regulation for appropriate circadian clock functioning (Nakahata et al. 2009, EckelMahan et al. 2013). Less is known about the circadian regulation of Nmrk1 and 2. Nmrk1 was recently shown to be circadian regulated in mouse liver tissue and interestingly, like Nampt, Nmrk1 expression was dysregulated in clockdisrupted mice (Mauvoisin et al. 2017).

\section{NAD+ precursors as therapeutic interventions}

$\mathrm{NAD}^{+}$has long been associated with disease with symptoms of pellagra first described in the 1800s (Pitche 2005). Pellagra is most commonly caused by malnutrition - more specifically a deficiency in vitamin $\mathrm{B} 3 \mathrm{NAD}^{+}$precursors and is classically characterised by the triad of symptoms; dermatitis, diarrhoea and dementia. Pellagra is historically associated with diets rich in maize, which presents little nutritional value and it was later found that dietary supplementation with $\mathrm{NAD}^{+}$precursors successfully treated pellagra (Pitche 2005, Naveen et al. 2013).

Since the role of $\mathrm{NAD}^{+}$as a central metabolic signalling molecule was discovered, there has been a substantial number of studies associating $\mathrm{NAD}^{+}$availability to metabolic health. A decline in $\mathrm{NAD}^{+}$in multiple tissues and cell types has been linked to the pathophysiology of ageing and chronic disease states including type II diabetes, neurodegeneration, liver disease and cachexia (Koltai et al. 2010, Braidy et al. 2011, Yoshino et al. 2011, Massudi et al. 2012, Gomes et al. 2013, Long et al. 2015, Camacho-Pereira et al. 2016, Mills et al. 2016, Zhou et al. 2016). Many of these studies implicate reduced SIRT expression and/or activity following a loss of $\mathrm{NAD}^{+}$and consequently the activity of key SIRT-mediated targets (Koltai et al. 2010, Braidy et al. 2011, Yoshino et al. 2011, Massudi et al. 2012, Gomes et al. 2013, Long et al. 2015, Camacho-Pereira et al. 2016, Zhou et al. 2016). Loss of $\mathrm{NAD}^{+}$in many of these scenarios may, at least in part, be attributed to elevated PARP activity (Pillai et al. 2005, Braidy et al. 2011, Massudi et al. 2012, Lehmann et al. 2016). With increased DNA damage, a hallmark factor of ageing and a consequence of chronic disease, increased PARP activity to induce DNA repair processes can be detrimental to metabolic homeostasis with a decline to cellular $\mathrm{NAD}^{+}$availability leading to reduced SIRT activity (Decker \& Muller 2002, Bai et al. 2011a, Massudi et al. 2012). The importance of $\mathrm{NAD}^{+}$-consuming enzyme crosstalk has previously been established through models of PARP excess and deletion. These models demonstrate a concomitant decrease in $\mathrm{NAD}^{+}$and SIRT activity following PARP overexpression and an increase in $\mathrm{NAD}^{+}$content and SIRT-mediated signalling when PARP activity is inhibited (Mangerich et al. 2010, Bai et al. 2011a,b, Luo \& Kraus 2012, Mohamed et al. 2014). PARP inhibitors have already shown promise as anticancer agents and now may also be valuable therapeutics against metabolic disease, with PARP inhibition resulting in enhanced oxidative metabolism in mouse models (Bai et al. 2011a,b, To et al. 2014). Recent studies have also implicated CD38 in agerelated mitochondrial dysfunction. An increase in CD38 expression was determined in metabolic tissues such as liver, adipose and muscle. Detrimental effects of CD38 in ageing, mediated via a SIRT3 mechanism, were to some extent reversed in CD38 loss-of-function mouse models (Camacho-Pereira et al. 2016).

The knowledge that enhancing $\mathrm{NAD}^{+}$can induce positive metabolic effects mediated through the induction of SIRT has additionally resulted in a vast array of studies looking at the efficacy of using $\mathrm{NAD}^{+}$precursors to boost $\mathrm{NAD}^{+}$(Mouchiroud et al. 2013, Fang et al. 2017, Rajman et al. 2018). NA derivatives have been used clinically for many years, notably in treatment of hypercholesterolemia; however, action on the GPR109A receptor causes undesirable flushing side effects in a large proportion of patients and ultimately leads to poor compliance (Taskinen \& Nikkila 1988, Gille et al. 2008, van de Weijer et al. 2015). There has since been major interest in the use of alternative $\mathrm{NAD}^{+}$precursors that do not activate the GPR109A. Although nicotinamide has been shown to be effective in boosting $\mathrm{NAD}^{+}$in tissues, concerns regarding the requirement of high doses, which may exert an inhibitory effect on SIRT activity and reduce efficacy

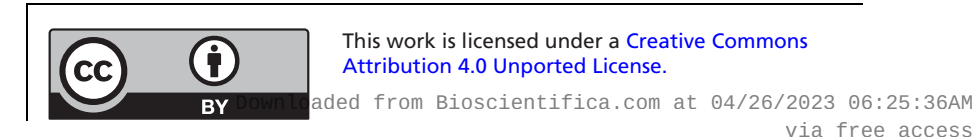


(Collins \& Chaykin 1972, Bender \& Olufunwa 1988, Bitterman et al. 2002, Liu et al. 2009, Mitchell et al. 2018), have led to a surge of research focussing on the therapeutic potential of NR and NMN (Elhassan et al. 2017).

Both NR and NMN have been shown as effective $\mathrm{NAD}^{+}$enhancers in numerous models following supplementation without any notable adverse effects reported to date (Yoshino et al. 2011, Cantó et al. 2012, Khan et al. 2014, Mills et al. 2016, Trammell et al. 2016b, Uddin et al. 2016, Wang et al. 2016, Zhang et al. 2016). The number of studies investigating their therapeutic potential has grown rapidly in recent years. Although these studies have often focussed on one or the other compound, similar and overlapping effects of either NR or NMN supplementation have been reported (Fig. 3 - lower panel). These include NR-mediated $\mathrm{NAD}^{+}$repletion in ageing mice protecting against muscle degeneration, and similarly delayed muscle stem cell senescence in models of muscular dystrophy through improved mitochondrial function resulting in enhanced regenerative capacity and more favourable phenotypes (Zhang et al. 2016). Importantly, the beneficial regenerative effects of NR extended to neural and melanocyte stem cells where it was shown to delay senescence and extend life span (Zhang et al. 2016). NMN supplementation also exhibited positive effects on neurogenesis in aged mice by preserving the neural stem/progenitor cell pool (Stein \& Imai 2014). In models of cardiac pathology including ischaemia and reperfusion, heart failure and hypertrophy supplementation with either NMN or NR has resulted in improved outcomes (Yamamoto et al. 2014, Diguet et al. 2017). In metabolic diseases of obesity, diabetes and nonalcoholic fatty liver disease (NAFLD) protective effects of exogenous NR or NMN delivery include enhanced metabolic flexibility, mitochondrial function, improved glucose tolerance, reduced weight gain and prevention of hepatic steatosis and other pathological factors of NAFLD (Yoshino et al. 2011, Cantó et al. 2012, Trammell et al. 2016b, Zhou et al. 2016, Shi et al. 2017) (Fig. 3). There have been many more studies recently published investigating the in vivo effects of NR and NMN supplementation in a variety of disease models, and a more detailed analysis of these has been well described in a number of recent reviews (Fang et al., Rajman et al. 2018).

Currently, the majority of work looking at the benefits of vitamin B3 supplementation has been carried out using animal models; thus, the translational potential to humans is still unclear. Currently, a number of clinical trials focussing on NR and NMN supplementation have recently been completed or are still ongoing. The first clinical study with NR - a double-blind, randomised pharmacokinetic study with 12 participants - found a single oral dose of $1000 \mathrm{mg}$ NR raised circulatory $\mathrm{NAD}^{+}$levels by 2.7-fold; interestingly, $\mathrm{NAD}^{+}$metabolomics also identified NAAD as a highly sensitive biomarker for $\mathrm{NAD}^{+}$(Trammell et al. $2016 a$ ). In another non-randomised clinical study with eight subjects, a dose-dependent increase in $\mathrm{NAD}^{+}$was found with $250-1000 \mathrm{mg} /$ day NR was orally administered over 9 days with a maximal two-fold increase seen in $\mathrm{NAD}^{+}$ (Airhart et al. 2017). An 8-week double-blind, randomised clinical trial $(n=118)$ assessing the efficacy and safety of repeat dose NR in combination with the polyphenol molecule pterostilbene, collectively known as NRPT, dosed at either $250 \mathrm{mg} \mathrm{NR} / 50 \mathrm{mg}$ PT or $500 \mathrm{mg} \mathrm{NR} / 100 \mathrm{mg}$ PT vs a placebo control group has been conducted (Dellinger et al. 2017). This study provided positive results regarding the safety of repeat dose NRPT and also showed a significant increase in whole blood $\mathrm{NAD}^{+}$. In addition, potentially positive effects were observed regarding liver function, which may become more apparent in larger scale clinical trials (Dellinger et al. 2017). In addition, an in-depth analysis of chronic NR supplementation (500 mg, twice/day) has recently been investigated in a randomised 6-week, double-blind, placebo-controlled, crossover clinical trial in healthy middle-aged to older adults $(n=24)$. The results from this latest trial further supported previous studies, showing that at this dose, chronic NR was well tolerated by subjects and was also able to enhance NAD+ levels of blood cells (Martens et al. 2018). Interestingly, the study also demonstrated some positive trends following NR supplementation in terms of cardiovascular health including NR potentially reducing systolic blood pressure and arterial stiffness (de Picciotto et al. 2016). Again, larger scale clinical trials are now required to establish the potential of NR to exert beneficial effects on these cardiovascular parameters and beyond. There are several ongoing clinical studies that are currently further assessing the safety, efficacy and impact of either NR or NMN supplementation on a wide range of health parameters including vascular endothelial function, immune function, kidney function, muscle mitochondrial function, cognitive function and energy metabolism (see clinicaltrials.gov). Although there is still much to learn regarding the clinical impact of NR and NMN supplementation, currently no adverse effects have been reported (Trammell et al. 2016a, Airhart et al. 2017).

Despite many studies reporting beneficial outcomes in disease models, and the absence of adverse effects from the clinical studies to date, there is still some concern about possible unwanted effects of elevating $\mathrm{NAD}^{+}$

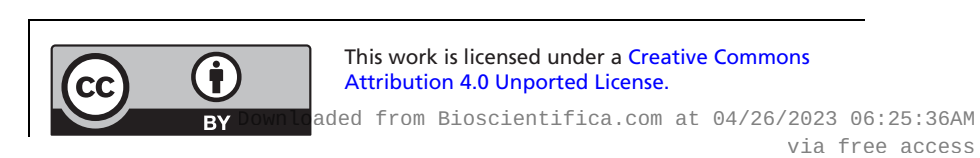


with particular focus surrounding immune responses. Numerous mechanistic studies have provided rationale for these concerns with an association found between raised $\mathrm{NAD}^{+}$levels and pro-inflammatory effects (Van Gool et al. 2009, Preyat et al. 2016, Gerner et al. 2017). Notably, secretion of the pro-inflammatory cytokine TNF- $\alpha$ is responsive to intracellular NAD+ levels via a proposed SIRT6-based mechanism with loss of SIRT function able to reverse these effects (Van Gool et al. 2009). Although typically thought to be a pro-survival factor, $\mathrm{NAD}^{+}$has also been found to regulate TNF-induced necroptosis, a regulated form of necrosis, via a SIRTdependent mechanism (Preyat et al. 2016). SIRT1 has also been identified to induce pro-inflammatory effects by promoting $\mathrm{T}$ helper 17 effector cell generation and function (Lim et al. 2015). The use of NAMPT inhibitors to deplete cellular $\mathrm{NAD}^{+}$levels has been explored in models of malignancy and inflammation with some studies showing promising effects (Montecucco et al. 2013b). For example, in disease models of colitis where NAMPT is upregulated in response to an increased turnover of $\mathrm{NAD}^{+}$as a result of enhanced activity of $\mathrm{NAD}^{+}$-consuming enzymes, NAMPT inhibition was able to markedly supress key inflammatory processes (Gerner et al. 2017). Similar anti-inflammatory effects have been seen in models of arthritis, experimental autoimmune encephalomyelitis and myocardial ischaemia/reperfusion (Busso et al. 2008, Bruzzone et al. 2009, Montecucco et al. 2013a,b). Although to date there have been no reports of pro-inflammatory effects following vitamin B3 supplementation, these effects may become apparent following long-term precursor supplementation or in certain inflammatory disease states. As many of these pro-inflammatory mechanisms are thought to be mediated by SIRT activity perhaps the rise in nicotinamide, a known inhibitor of SIRT activity, consistently found following NR and NMN supplementation may provide a means of protection against deleterious effects (Bitterman et al. 2002).

\section{Future research avenues}

Understanding of the importance of $\mathrm{NAD}^{+}$in metabolic health has greatly advanced in recent years and currently research is now focussed on further defining firstly the key pathways vital to maintaining $\mathrm{NAD}^{+}$homeostasis but secondly establishing the most useful pathways to manipulate for enhanced $\mathrm{NAD}^{+}$turnover. Many research challenges still remain including organism, tissue and organelle specificity as well circadian signalling and technical limitations for quantification. The identification of more robust biomarkers to monitor $\mathrm{NAD}^{+}$turnover in health and disease would be extremely valuable.

In terms of clinical importance, many questions are still unanswered regarding the translational likelihood of NR and NMN salvage via the NRK enzymes. These include delivery of appropriate levels of substrate to target tissue, the best route of substrate delivery, dosing and timing taking into account circadian fluctuations in enzymes expression.

Furthermore, the function of NRK2 is still unclear, although it appears to play a redundant role in $\mathrm{NAD}^{+}$ biosynthesis along with NRK1, at least in unchallenged models, its highly regulated expression particularly in times of stress suggest it may have role beyond $\mathrm{NAD}^{+}$ metabolism.

\section{Concluding remarks}

The requirement of NRK1 and 2 to utilise exogenous NR and NMN has led to a new found interest into the regulation of this alternative $\mathrm{NAD}^{+}$pathway. The notion of using $\mathrm{NAD}^{+}$precursors to boost $\mathrm{NAD}^{+}$is now beginning to see translation into human studies, appearing to be safe, naturally available, and having the potential to improve health outcomes across a large range of pathophysiological scenarios. NR and NMN supplementation are at the forefront of several clinical trials as a result of mounting evidence from a vast array of in vivo studies supporting their therapeutic potential. Despite this, there is still much more to learn about the NRK enzymes and how best to target $\mathrm{NAD}^{+}$boosting therapies in order for them to maximise their effects. In terms of $\mathrm{NAD}^{+}$biosynthesis, NRK1 appears to play a more crucial role upon exogenous delivery of NR. NRK2 is much more highly regulated with expression typically muscle specific except in times of injury of energetic stress where large changes to expression have been observed. Further work is now necessary to determine whether this induction is a purely adaptive response to acute loss of energy homeostasis or if there is a potential alternative function for NRK2 beyond $\mathrm{NAD}^{+}$metabolism. The induction of NRK activity may also point to the tissues and scenarios in which NR and NMN may be most therapeutically effective.

\section{Declaration of interest}

The authors declare that there is no conflict of interest that could be perceived as prejudicing the impartiality of this review.

\section{Funding}

GGL is supported by a Wellcome Trust Senior Fellowship (grant number104612/Z/14/Z).

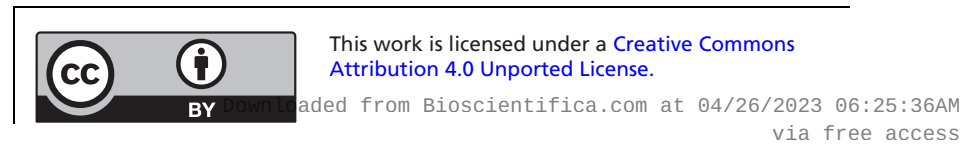




\section{References}

Agerholm M, Dall M, Jensen BAH, Prats C, Madsen S, Basse AL, Graae AS, Risis S, Goldenbaum J, Quistorff B, et al. 2018 Perturbations of $\mathrm{NAD}(+)$ salvage systems impact mitochondrial function and energy homeostasis in mouse myoblasts and intact skeletal muscle. American Journal of Physiology-Endocrinology and Metabolism 314 E377-E395. (https://doi.org/10.1152/ ajpendo.00213.2017)

Aguilar CA, Shcherbina A, Ricke DO, Pop R, Carrigan CT, Gifford CA, Urso ML, Kottke MA \& Meissner A 2015 In vivo monitoring of transcriptional dynamics after lower-limb muscle injury enables quantitative classification of healing. Scientific Reports 513885. (https://doi.org/10.1038/srep13885)

Airhart SE, Shireman LM, Risler LJ, Anderson GD, Nagana Gowda GA, Raftery D, Tian R, Shen DD \& O'Brien KD 2017 An open-label, nonrandomized study of the pharmacokinetics of the nutritional supplement nicotinamide riboside (NR) and its effects on blood NAD+ levels in healthy volunteers. PLOS ONE 12 e0186459. (https:// doi.org/10.1371/journal.pone.0186459)

Aksoy P, White TA, Thompson M \& Chini EN 2006 Regulation of intracellular levels of NAD: a novel role for CD38. Biochemical and Biophysical Research Communications 345 1386-1392. (https://doi. org/10.1016/j.bbrc.2006.05.042)

Alano CC, Tran A, Tao R, Ying W, Karliner JS \& Swanson RA 2007 Differences among cell types in $\mathrm{NAD}(+)$ compartmentalization: a comparison of neurons, astrocytes, and cardiac myocytes. Journal of Neuroscience Research 85 3378-3385. (https://doi.org/10.1002/ jnr.21479)

Bai P, Canto C, Brunyanszki A, Huber A, Szanto M, Cen Y, Yamamoto H, Houten SM, Kiss B, Oudart H, et al. 2011a PARP-2 regulates SIRT1 expression and whole-body energy expenditure. Cell Metabolism 13 450-460. (https://doi.org/10.1016/j.cmet.2011.03.013)

Bai P, Cantó C, Oudart H, Brunyánszki A, Cen Y, Thomas C, Yamamoto H, Huber A, Kiss B, Houtkooper Riekelt H, et al. 2011b PARP-1 inhibition increases mitochondrial metabolism through SIRT1 activation. Cell Metabolism 13 461-468. (https://doi. org/10.1016/j.cmet.2011.03.004)

Belenky P, Stebbins R, Bogan KL, Evans CR \& Brenner C 2011 Nrt1 and Tna1-independent export of NAD+ precursor vitamins promotes $\mathrm{NAD}+$ homeostasis and allows engineering of vitamin production. PLoS ONE 6 e19710. (https://doi.org/10.1371/journal.pone.0019710)

Bender DA \& Olufunwa R 1988 Utilization of tryptophan, nicotinamide and nicotinic acid as precursors for nicotinamide nucleotide synthesis in isolated rat liver cells. British Journal of Nutrition $\mathbf{5 9}$ 279-287. (https://doi.org/10.1079/BJN19880035)

Bender DA, Magboul BI \& Wynick D 1982 Probable mechanisms of regulation of the utilization of dietary tryptophan, nicotinamide and nicotinic acid as precursors of nicotinamide nucleotides in the rat. British Journal of Nutrition 48 119-127. (https://doi.org/10.1079/ BJN19820094)

Berger F, Ramirez-Hernandez MH \& Ziegler M 2004 The new life of a centenarian: signalling functions of $\mathrm{NAD}(\mathrm{P})$. Trends in Biochemical Sciences 29 111-118. (https://doi.org/10.1016/j.tibs.2004.01.007)

Bieganowski P \& Brenner C 2004 Discoveries of nicotinamide riboside as a nutrient and conserved NRK genes establish a Preiss-Handler independent route to NAD+ in fungi and humans. Cell $\mathbf{1 1 7}$ 495-502. (https://doi.org/10.1016/S0092-8674(04)00416-7)

Bitterman KJ, Anderson RM, Cohen HY, Latorre-Esteves M \& Sinclair DA 2002 Inhibition of silencing and accelerated aging by nicotinamide, a putative negative regulator of yeast sir2 and human SIRT1. Journal of Biological Chemistry 277 45099-45107. (https://doi.org/10.1074/ jbc.M205670200)

Bogan KL \& Brenner C 2008 Nicotinic acid, nicotinamide, and nicotinamide riboside: a molecular evaluation of NAD+ precursor vitamins in human nutrition. Annual Review of Nutrition 28 115-130. (https://doi.org/10.1146/annurev.nutr.28.061807.155443)

Boily G, Seifert EL, Bevilacqua L, He XH, Sabourin G, Estey C, Moffat C, Crawford S, Saliba S, Jardine K, et al. 2008 SirT1 regulates energy metabolism and response to caloric restriction in mice. PLOS ONE $\mathbf{3}$ e1759. (https://doi.org/10.1371/journal.pone.0001759)

Boshoff HI, Xu X, Tahlan K, Dowd CS, Pethe K, Camacho LR, Park TH, Yun CS, Schnappinger D, Ehrt S, et al. 2008 Biosynthesis and recycling of nicotinamide cofactors in mycobacterium tuberculosis. An essential role for NAD in nonreplicating bacilli. Journal of Biological Chemistry 283 19329-19341. (https://doi.org/10.1074/jbc. M800694200)

Braidy N, Guillemin GJ, Mansour H, Chan-Ling T, Poljak A \& Grant R 2011 Age related changes in NAD+ metabolism oxidative stress and Sirt1 activity in wistar rats. PLOS ONE 6 e19194. (https://doi. org/10.1371/journal.pone.0019194)

Bruzzone S, Fruscione F, Morando S, Ferrando T, Poggi A, Garuti A, D’Urso A, Selmo M, Benvenuto F, Cea M, et al. 2009 Catastrophic NAD+ depletion in activated T lymphocytes through Nampt inhibition reduces demyelination and disability in EAE. PLOS ONE 4 e7897. (https://doi.org/10.1371/journal.pone.0007897)

Busso N, Karababa M, Nobile M, Rolaz A, Van Gool F, Galli M, Leo O, So A \& De Smedt T 2008 Pharmacological inhibition of nicotinamide phosphoribosyltransferase/visfatin enzymatic activity identifies a new inflammatory pathway linked to NAD. PLOS ONE 3 e2267. (https://doi.org/10.1371/journal.pone.0002267)

Camacho-Pereira J, Tarrago MG, Chini CC, Nin V, Escande C, Warner GM, Puranik AS, Schoon RA, Reid JM, Galina A, et al. 2016 CD38 dictates age-related NAD decline and mitochondrial dysfunction through an SIRT3-dependent mechanism. Cell Metabolism 23 1127-1139. (https://doi.org/10.1016/j. cmet.2016.05.006)

Cambronne XA, Stewart ML, Kim D, Jones-Brunette AM, Morgan RK, Farrens DL, Cohen MS \& Goodman RH 2016 Biosensor reveals multiple sources for mitochondrial NAD(+). Science 352 1474-1477. (https://doi.org/10.1126/science.aad5168)

Canto C, Gerhart-Hines Z, Feige JN, Lagouge M, Noriega L, Milne JC, Elliott PJ, Puigserver P \& Auwerx J 2009 AMPK regulates energy expenditure by modulating NAD+ metabolism and SIRT1 activity. Nature 458 1056-1060. (https://doi.org/10.1038/nature07813)

Canto C, Jiang LQ, Deshmukh AS, Mataki C, Coste A, Lagouge M, Zierath JR \& Auwerx J 2010 Interdependence of AMPK and SIRT1 for metabolic adaptation to fasting and exercise in skeletal muscle. Cell Metabolism 11 213-219. (https://doi.org/10.1016/j.cmet.2010.02.006)

Cantó C, Houtkooper Riekelt H, Pirinen E, Youn Dou Y, Oosterveer Maaike H, Cen Y, Fernandez-Marcos Pablo J, Yamamoto H, Andreux Pénélope A, Cettour-Rose P, et al. 2012 The NAD+ precursor nicotinamide riboside enhances oxidative metabolism and protects against high-fat diet-induced obesity. Cell Metabolism 15 838-847. (https://doi.org/10.1016/j.cmet.2012.04.022)

Casazza JP \& Veech RL 1986 The content of pentose-cycle intermediates in liver in starved, fed ad libitum and meal-fed rats. Biochemical Journal 236 635-641. (https://doi.org/10.1042/bj2360635)

Charron MJ \& Bonner-Weir S 1999 Implicating PARP and NAD+ depletion in type I diabetes. Nature Medicine 5 269-270. (https://doi. org/10.1038/6479)

Collins PB \& Chaykin S 1972 The management of nicotinamide and nicotinic acid in the mouse. Journal of Biological Chemistry $\mathbf{2 4 7}$ 778-783.

Dali-Youcef N, Lagouge M, Froelich S, Koehl C, Schoonjans K \& Auwerx J 2007 Sirtuins: the 'magnificent seven', function, metabolism and longevity. Annals of Medicine 39 335-345. (https:// doi.org/10.1080/07853890701408194)

De Flora A, Franco L, Guida L, Bruzzone S \& Zocchi E 1998 Ectocellular CD38-catalyzed synthesis and intracellular $\mathrm{Ca}(2+)$-mobilizing activity http://jme.endocrinology-journals.org https://doi.org/10.1530/JME-18-0085
C 2018 The authors Published by Bioscientifica Ltd. Printed in Great Britain

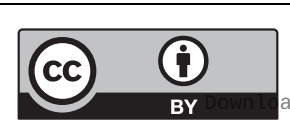

This work is licensed under a Creative Common Attribution 4.0 Unported License. ded from Bioscientifica.com at 04/26/2023 06:25:36AM 
of cyclic ADP-ribose. Cell Biochemistry and Biophysics 28 45-62. (https://doi.org/10.1007/BF02738309)

De Ingeniis J, Kazanov MD, Shatalin K, Gelfand MS, Osterman AL \& Sorci L 2012 Glutamine versus ammonia utilization in the NAD synthetase family. PLOS ONE 7 e39115. (https://doi.org/10.1371/ journal.pone.0039115)

de Picciotto NE, Gano LB, Johnson LC, Martens CR, Sindler AL, Mills KF, Imai S \& Seals DR 2016 Nicotinamide mononucleotide supplementation reverses vascular dysfunction and oxidative stress with aging in mice. Aging Cell 15 522-530. (https://doi.org/10.1111/ acel.12461)

Decker P \& Muller S 2002 Modulating poly (ADP-ribose) polymerase activity: potential for the prevention and therapy of pathogenic situations involving DNA damage and oxidative stress. Current Pharmaceutical Biotechnology 3 275-283. (https://doi. org/10.2174/1389201023378265)

Dellinger RW, Santos SR, Morris M, Evans M, Alminana D, Guarente L \& Marcotulli E 2017 Repeat dose NRPT (nicotinamide riboside and pterostilbene) increases $\mathrm{NAD}(+)$ levels in humans safely and sustainably: a randomized, double-blind, placebo-controlled study. NPJ Aging and Mechanisms of Disease 3 17. (https://doi.org/10.1038/ s41514-017-0016-9)

Diguet N, Trammell SAJ, Tannous C, Deloux R, Piquereau J, Mougenot N, Gouge A, Gressette M, Manoury B, Blanc J, et al. 2018 Nicotinamide riboside preserves cardiac function in a mouse model of dilated cardiomyopathy. Circulation 137 2256-2273.

Dölle C \& Ziegler M 2009 Application of a coupled enzyme assay to characterize nicotinamide riboside kinases. Analytical Biochemistry 385 377-379. (https://doi.org/10.1016/j.ab.2008.10.033)

Dolle C, Skoge RH, Vanlinden MR \& Ziegler M 2013 NAD biosynthesis in humans - enzymes, metabolites and therapeutic aspects. Current Topics in Medicinal Chemistry 13 2907-2917. (https://doi.org/10.2174/ 15680266113136660206)

Easlon E, Tsang F, Skinner C, Wang C \& Lin SJ 2008 The malateaspartate NADH shuttle components are novel metabolic longevity regulators required for calorie restriction-mediated life span extension in yeast. Genes and Development 22 931-944. (https://doi. org/10.1101/gad.1648308)

Eckel-Mahan Kristin L, Patel Vishal R, de Mateo S, Orozco-Solis R, Ceglia Nicholas J, Sahar S, Dilag-Penilla Sherry A, Dyar Kenneth A, Baldi P \& Sassone-Corsi P 2013 Reprogramming of the circadian clock by nutritional challenge. Cell 155 1464-1478. (https://doi. org/10.1016/i.cell.2013.11.034)

El-Khamisy SF, Masutani M, Suzuki H \& Caldecott KW 2003 A requirement for PARP-1 for the assembly or stability of XRCC1 nuclear foci at sites of oxidative DNA damage. Nucleic Acids Research 31 5526-5533. (https://doi.org/10.1093/nar/gkg761)

Elhassan YS, Philp AA \& Lavery GG 2017 Targeting NAD+ in metabolic disease: new insights into an old molecule. Journal of the Endocrine Society 1 816-835. (https://doi.org/10.1210/js.2017-00092)

Euler-Chelpin HV 1966 Fermentation of sugars and fermentative enzymes. In Nobel Lectures, Chemistry 1922-1941, 144-155. Amsterdam: Elsevier Publishing Company.

Fang EF, Lautrup S, Hou Y, Demarest TG, Croteau DL, Mattson MP \& Bohr VA 2017 NAD+ in aging: molecular mechanisms and translational implications. Trends in Molecular Medicine 23 899-916. (https://doi.org/10.1016/j.molmed.2017.08.001)

Feige JN, Lagouge M, Canto C, Strehle A, Houten SM, Milne JC, Lambert PD, Mataki C, Elliott PJ \& Auwerx J 2008 Specific SIRT1 activation mimics low energy levels and protects against dietinduced metabolic disorders by enhancing fat oxidation. Cell Metabolism 8 347-358. (https://doi.org/10.1016/j.cmet.2008.08.017)

Fernandez-Marcos PJ, Jeninga EH, Canto C, Harach T, de Boer VCJ, Andreux P, Moullan N, Pirinen E, Yamamoto H, Houten SM, et al. 2012 Muscle or liver-specific Sirt3 deficiency induces hyperacetylation of mitochondrial proteins without affecting global metabolic homeostasis. Scientific Reports 2 425. (https://doi. org/10.1038/srep00425)

Fletcher RS, Ratajczak J, Doig CL, Oakey LA, Callingham R, Da Silva Xavier G, Garten A, Elhassan YS, Redpath P, Migaud ME, et al. 2017 Nicotinamide riboside kinases display redundancy in mediating nicotinamide mononucleotide and nicotinamide riboside metabolism in skeletal muscle cells. Molecular Metabolism 6 819-832. (https://doi.org/10.1016/j.molmet.2017.05.011)

Frederick DW, Loro E, Liu L, Davila A Jr, Chellappa K, Silverman IM, Quinn WJ 3rd, Gosai SJ, Tichy ED, Davis JG, et al. 2016 Loss of NAD homeostasis leads to progressive and reversible degeneration of skeletal muscle. Cell Metabolism 24 269-282. (https://doi. org/10.1016/j.cmet.2016.07.005)

Fukuhara A, Matsuda M, Nishizawa M, Segawa K, Tanaka M, Kishimoto K, Matsuki Y, Murakami M, Ichisaka T, Murakami H, et al. 2005 Visfatin: a protein secreted by visceral fat that mimics the effects of insulin. Science 307 426-430. (https://doi.org/10.1126/ science.1097243)

Garten A, Petzold S, Körner A, Imai S-I \& Kiess W 2009 Nampt: linking NAD biology, metabolism and cancer. Trends in Endocrinology and Metabolism 20 130-138. (https://doi. $\operatorname{org} / 10.1016 /$ j.tem.2008.10.004)

Garten A, Schuster S, Penke M, Gorski T, de Giorgis T \& Kiess W 2015 Physiological and pathophysiological roles of NAMPT and NAD metabolism. Nature Reviews Endocrinology 11 535-546. (https://doi. org/10.1038/nrendo.2015.117)

Gazzaniga F, Stebbins R, Chang SZ, McPeek MA \& Brenner C 2009 Microbial NAD metabolism: lessons from comparative genomics. Microbiology and Molecular Biology Reviews: MMBR 73 529-541. (https://doi.org/10.1128/MMBR.00042-08)

Gerner RR, Klepsch V, Macheiner S, Arnhard K, Adolph TE, Grander C, Wieser V, Pfister A, Moser P, Hermann-Kleiter N, et al. 2017 NAD metabolism fuels human and mouse intestinal inflammation. Gut Epub. (https://doi.org/10.1136/gutjnl-2017-314241)

Gille A, Bodor ET, Ahmed K \& Offermanns S 2008 Nicotinic acid: pharmacological effects and mechanisms of action. Annual Review of Pharmacology and Toxicology 48 79-106. (https://doi.org/10.1146/ annurev.pharmtox.48.113006.094746)

Gomes AP, Price NL, Ling AJ, Moslehi JJ, Montgomery MK, Rajman L, White JP, Teodoro JS, Wrann CD, Hubbard BP, et al. 2013 Declining $\mathrm{NAD}(+)$ induces a pseudohypoxic state disrupting nuclearmitochondrial communication during aging. Cell 155 1624-1638. (https://doi.org/10.1016/j.cell.2013.11.037)

Goody MF, Kelly MW, Lessard KN, Khalil A \& Henry CA 2010 Nrk2bmediated NAD+ production regulates cell adhesion and is required for muscle morphogenesis in vivo: Nrk2b and NAD+ in muscle morphogenesis. Developmental Biology 344 809-826. (https://doi. org/10.1016/j.ydbio.2010.05.513)

Goody MF, Kelly MW, Reynolds CJ, Khalil A, Crawford BD \& Henry CA 2012 NAD+ biosynthesis ameliorates a zebrafish model of muscular dystrophy. PLoS Biology 10 e1001409. (https://doi.org/10.1371/ journal.pbio.1001409)

Graeff R, Liu Q, Kriksunov IA, Kotaka M, Oppenheimer N, Hao Q \& Lee HC 2009 Mechanism of cyclizing NAD to cyclic ADP-ribose by ADP-ribosyl cyclase and CD38. Journal of Biological Chemistry 284 27629-27636. (https://doi.org/10.1074/jbc.M109.030965)

Gross JW, Rajavel M \& Grubmeyer C 1998 Kinetic mechanism of nicotinic acid phosphoribosyltransferase: implications for energy coupling. Biochemistry 37 4189-4199. (https://doi.org/10.1021/ bi972014w)

Ha HC \& Snyder SH 1999 Poly(ADP-ribose) polymerase is a mediator of necrotic cell death by ATP depletion. PNAS 96 13978-13982. (https://doi.org/10.1073/pnas.96.24.13978)

Hara N, Yamada K, Terashima M, Osago H, Shimoyama M \& Tsuchiya M 2003 Molecular identification of human glutamine- and ammoniadependent NAD synthetases carbon-nitrogen hydrolase domain

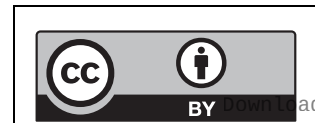

This work is licensed under a Creative Commons Attribution 4.0 Unported License. 
confers glutamine dependency. Journal of Biological Chemistry 278 10914-10921. (https://doi.org/10.1074/jbc.M209203200)

Hara N, Yamada K, Shibata T, Osago H \& Tsuchiya M 2011 Nicotinamide phosphoribosyltransferase/visfatin does not catalyze nicotinamide mononucleotide formation in blood plasma. PLOS ONE 6 e22781. (https://doi.org/10.1371/journal.pone.0022781)

Harasim E, Chabowski A \& Gorski J 2011 Lack of downstream insulinmimetic effects of visfatin/eNAMPT on glucose and fatty acid metabolism in skeletal muscles. Acta Physiologica 202 21-28. (https:// doi.org/10.1111/j.1748-1716.2011.02254.x)

Harden A \& Young WJ 1906 The alcoholic ferment of yeast-juice. Proceedings of the Royal Society B: Biological Sciences 78 369-375. (https://doi.org/10.1098/rspb.1906.0070)

Hasmann M \& Schemainda I 2003 FK866, a highly specific noncompetitive inhibitor of nicotinamide phosphoribosyltransferase, represents a novel mechanism for induction of tumor cell apoptosis. Cancer Research 63 7436-7442.

Hirschey MD, Shimazu T, Goetzman E, Jing E, Schwer B, Lombard DB, Grueter CA, Harris C, Biddinger S, Ilkayeva OR, et al. 2010 SIRT3 regulates mitochondrial fatty-acid oxidation by reversible enzyme deacetylation. Nature 464 121-125. (https://doi.org/10.1038/ nature08778)

Houtkooper RH, Canto C, Wanders RJ \& Auwerx J 2010 The secret life of NAD+: an old metabolite controlling new metabolic signaling pathways. Endocrine Reviews 31 194-223. (https://doi.org/10.1210/ er.2009-0026)

Houtkooper RH, Pirinen E \& Auwerx J 2012 Sirtuins as regulators of metabolism and healthspan. Nature Reviews Molecular Cell Biology 13 225-238. (https://doi.org/10.1038/nrm3293)

Jing E, Emanuelli B, Hirschey MD, Boucher J, Lee KY, Lombard D, Verdin EM \& Kahn CR 2011 Sirtuin-3 (Sirt3) regulates skeletal muscle metabolism and insulin signaling via altered mitochondrial oxidation and reactive oxygen species production. PNAS 108 14608-14613. (https://doi.org/10.1073/pnas.1111308108)

Jing E, O'Neill BT, Rardin MJ, Kleinridders A, Ilkeyeva OR, Ussar S, Bain JR, Lee KY, Verdin EM, Newgard CB, et al. 2013 Sirt3 regulates metabolic flexibility of skeletal muscle through reversible enzymatic deacetylation. Diabetes 62 3404-3417. (https://doi.org/10.2337/db12-1650)

Kauppinen TM, Gan L \& Swanson RA 2013 Poly(ADP-ribose) polymerase-1-induced NAD+ depletion promotes nuclear factor-kB transcriptional activity by preventing p65 de-acetylation. Biochimica et Biophysica Acta (BBA): Molecular Cell Research 1833 1985-1991. (https://doi.org/10.1016/j.bbamcr.2013.04.005)

Kendrick AA, Choudhury M, Rahman SM, McCurdy CE, Friederich M, Van Hove JLK, Watson PA, Birdsey N, Bao J, Gius D, et al. 2011 Fatty liver is associated with reduced SIRT3 activity and mitochondrial protein hyperacetylation. Biochemical Journal 433 505-514. (https:// doi.org/10.1042/BJ20100791)

Khan JA, Tao X \& Tong L 2006 Molecular basis for the inhibition of human NMPRTase, a novel target for anticancer agents. Nature Structural and Molecular Biology 13 582-588. (https://doi.org/10.1038/ nsmb1105)

Khan NA, Auranen M, Paetau I, Pirinen E, Euro L, Forsstrom S, Pasila L, Velagapudi V, Carroll CJ, Auwerx J, et al. 2014 Effective treatment of mitochondrial myopathy by nicotinamide riboside, a vitamin B3. EMBO Molecular Medicine 6 721-731. (https://doi.org/10.1002/ emmm.201403943)

Kieswich J, Sayers SR, Silvestre MF, Harwood SM, Yaqoob MM \& Caton PW 2016 Monomeric eNAMPT in the development of experimental diabetes in mice: a potential target for type 2 diabetes treatment. Diabetologia 59 2477-2486. (https://doi.org/10.1007/ s00125-016-4076-3)

Kitani T, Okuno S \& Fujisawa H 2003 Growth phase-dependent changes in the subcellular localization of pre-B-cell colony-enhancing factor. FEBS Letters 544 74-78. (https://doi.org/10.1016/S00145793(03)00476-9)
Koltai E, Szabo Z, Atalay M, Boldogh I, Naito H, Goto S, Nyakas C \& Radak Z 2010 Exercise alters SIRT1, SIRT6, NAD and NAMPT levels in skeletal muscle of aged rats. Mechanisms of Ageing and Development 131 21-28. (https://doi.org/10.1016/j.mad.2009.11.002)

Kornberg A 1991 For the Love of Enzymes: The Odyssey of a Biochemist. Cambridge, Mass.; London: Harvard University Press.

Kulikova V, Shabalin K, Nerinovski K, Dolle C, Niere M, Yakimov A, Redpath P, Khodorkovskiy M, Migaud ME, Ziegler M, et al. 2015 Generation, release, and uptake of the NAD precursor nicotinic acid riboside by human cells. Journal of Biological Chemistry 290 27124-27137. (https://doi.org/10.1074/jbc.M115.664458)

Kurnasov OV, Polanuyer BM, Ananta S, Sloutsky R, Tam A, Gerdes SY \& Osterman AL 2002 Ribosylnicotinamide kinase domain of NadR protein: identification and implications in NAD biosynthesis. Journal of Bacteriology 184 6906-6917. (https://doi.org/10.1128/ JB.184.24.6906-6917.2002)

Mouchiroud L, Houtkooper RH, Moullan N, Katsyuba E, Ryu D, Cantó C, Mottis A, Jo YS, Viswanathan M, Schoonjans K, , et al. 2013 The NAD+/Sirtuin pathway modulates longevity through activation of mitochondrial UPR and FOXO signaling. Cell $\mathbf{1 5 4}$ 430-441. (https://doi.org/10.1016/j.cell.2013.06.016)

Lavery GG, Walker EA, Turan N, Rogoff D, Ryder JW, Shelton JM, Richardson JA, Falciani F, White PC, Stewart PM, et al. 2008 Deletion of Hexose-6-phosphate dehydrogenase activates the unfolded protein response pathway and induces skeletal myopathy. Journal of Biological Chemistry 283 8453-8461. (https://doi.org/10.1074/jbc. M710067200)

Lehmann S, Costa AC, Celardo I, Loh SH \& Martins LM 2016 Parp mutations protect against mitochondrial dysfunction and neurodegeneration in a PARKIN model of Parkinson's disease. Cell Death and Disease 7 e2166. (https://doi.org/10.1038/cddis.2016.72)

Lim HW, Kang SG, Ryu JK, Schilling B, Fei M, Lee IS, Kehasse A, Shirakawa K, Yokoyama M, Schnolzer M, et al. 2015 SIRT1 deacetylates RORgammat and enhances Th17 cell generation. Journal of Experimental Medicine 212 607-617. (https://doi.org/10.1084/ jem.20132378)

Lin JB, Kubota S, Ban N, Yoshida M, Santeford A, Sene A, Nakamura R, Zapata N, Kubota M, Tsubota K, et al. 2016 NAMPT-mediated NAD(+) biosynthesis is essential for vision in mice. Cell Reports $\mathbf{1 7}$ 69-85. (https://doi.org/10.1016/j.celrep.2016.08.073)

Liu D, Gharavi R, Pitta M, Gleichmann M \& Mattson MP 2009 Nicotinamide prevents NAD+ depletion and protects neurons against excitotoxicity and cerebral ischemia: NAD+ consumption by SIRT1 may endanger energetically compromised neurons. NeuroMolecular Medicine 11 28-42. (https://doi.org/10.1007/s12017-009-8058-1)

Long AN, Owens K, Schlappal AE, Kristian T, Fishman PS \& Schuh RA 2015 Effect of nicotinamide mononucleotide on brain mitochondrial respiratory deficits in an Alzheimer's disease-relevant murine model. BMC Neurology 15 19. (https://doi.org/10.1186/s12883-015-0272-x)

Luo X \& Kraus WL 2012 On PAR with PARP: cellular stress signaling through poly(ADP-ribose) and PARP-1. Genes and Development 26 417-432. (https://doi.org/10.1101/gad.183509.111)

Mangerich A, Herbach N, Hanf B, Fischbach A, Popp O, MorenoVillanueva M, Bruns OT \& Burkle A 2010 Inflammatory and agerelated pathologies in mice with ectopic expression of human PARP-1. Mechanisms of Ageing and Development 131 389-404. (https:// doi.org/10.1016/j.mad.2010.05.005)

Mao Z, Hine C, Tian X, Van Meter M, Au M, Vaidya A, Seluanov A \& Gorbunova V 2011 SIRT6 promotes DNA repair under stress by activating PARP1. Science 332 1443-1446. (https://doi.org/10.1126/ science.1202723)

Martens CR, Denman BA, Mazzo MR, Armstrong ML, Reisdorph N, McQueen MB, Chonchol M \& Seals DR 2018 Chronic nicotinamide riboside supplementation is well-tolerated and elevates $\mathrm{NAD}(+)$ in healthy middle-aged and older adults. Nature Communications 9 1286. (https://doi.org/10.1038/s41467-018-03421-7)

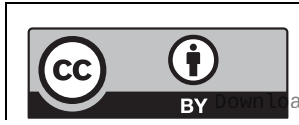

This work is licensed under a Creative Commons Attribution 4.0 Unported License. 
Massudi H, Grant R, Braidy N, Guest J, Farnsworth B \& Guillemin GJ 2012 Age-associated changes in oxidative stress and NAD+ metabolism in human tissue. PLOS ONE 7 e42357. (https://doi. org/10.1371/journal.pone.0042357)

Mauvoisin D, Atger F, Dayon L, Núñez Galindo A, Wang J, Martin E, Da Silva L, Montoliu I, Collino S, Martin F-P, et al. 2017 Circadian and feeding rhythms orchestrate the diurnal liver acetylome. Cell Reports 20 1729-1743. (https://doi.org/10.1016/j.celrep.2017.07.065)

Mills KF, Yoshida S, Stein LR, Grozio A, Kubota S, Sasaki Y, Redpath P, Migaud ME, Apte RS, Uchida K, et al. 2016 Long-term administration of nicotinamide mononucleotide mitigates age-associated physiological decline in mice. Cell Metabolism 24 795-806. (https:// doi.org/10.1016/j.cmet.2016.09.013)

Mitchell SJ, Bernier M, Aon MA, Cortassa S, Kim EY, Fang EF, Palacios HH, Ali A, Navas-Enamorado I, Di Francesco A, et al. 2018 Nicotinamide improves aspects of healthspan, but not lifespan, in mice. Cell Metabolism 27 667.e664-676.e664. (https://doi. org/10.1016/j.cmet.2018.02.001)

Mohamed JS, Hajira A, Pardo PS \& Boriek AM 2014 MicroRNA-149 inhibits PARP-2 and promotes mitochondrial biogenesis via SIRT-1/ PGC-1alpha network in skeletal muscle. Diabetes 63 1546-1559. (https://doi.org/10.2337/db13-1364)

Montecucco F, Bauer I, Braunersreuther V, Bruzzone S, Akhmedov A, Lüscher TF, Speer T, Poggi A, Mannino E, Pelli G, et al. 2013a Inhibition of nicotinamide phosphoribosyltransferase reduces neutrophil-mediated injury in myocardial infarction. Antioxidants and Redox Signaling 18 630-641. (https://doi.org/10.1089/ ars.2011.4487)

Montecucco F, Cea M, Bauer I, Soncini D, Caffa I, Lasiglie D, Nahimana A, Uccelli A, Bruzzone S \& Nencioni A 2013b Nicotinamide phosphoribosyltransferase (NAMPT) inhibitors as therapeutics: rationales, controversies, clinical experience. Current Drug Targets 14 637-643. (https://doi.org/10.2174/138945011131406 0003)

Mori V, Amici A, Mazzola F, Di Stefano M, Conforti L, Magni G, Ruggieri S, Raffaelli N \& Orsomando G 2014 Metabolic profiling of alternative NAD biosynthetic routes in mouse tissues. PLOS ONE 9 e113939. (https://doi.org/10.1371/journal.pone.0113939)

Mukherjee S, Chellappa K, Moffitt A, Ndungu J, Dellinger RW, Davis JG, Agarwal B \& Baur JA 2017 Nicotinamide adenine dinucleotide biosynthesis promotes liver regeneration. Hepatology 65 616-630. (https://doi.org/10.1002/hep.28912)

Nakahata Y, Sahar S, Astarita G, Kaluzova M \& Sassone-Corsi P 2009 Circadian control of the NAD ${ }^{+}$salvage pathway by CLOCK-SIRT1. Science 324 654-657. (https://doi.org/10.1126/science.1170803)

Naveen KN, Pai VV, Bagalkot P, Kulkarni V, Rashme P \& Athanikar SB 2013 Pellagra in a child - a rare entity. Nutrition 29 1426-1428. (https://doi.org/10.1016/j.nut.2013.05.020)

Nielsen KN, Peics J, Ma T, Karavaeva I, Dall M, Chubanava S, Basse AL, Dmytriyeva O, Treebak JT \& Gerhart-Hines Z 2018 NAMPT-mediated NAD+ biosynthesis is indispensable for adipose tissue plasticity and development of obesity. Molecular Metabolism 11 178-188. (https:// doi.org/10.1016/j.molmet.2018.02.014)

Nikiforov A, Dölle C, Niere M \& Ziegler M 2011 Pathways and subcellular compartmentation of NAD biosynthesis in human cells: from entry of extracellular precursors to mitochondrial nad generation. Journal of Biological Chemistry 286 21767-21778. (https:// doi.org/10.1074/jbc.M110.213298)

Pillai JB, Isbatan A, Imai S \& Gupta MP 2005 Poly(ADP-ribose) polymerase-1-dependent cardiac myocyte cell death during heart failure is mediated by NAD+ depletion and reduced Sir2alpha deacetylase activity. Journal of Biological Chemistry 280 43121-43130. (https://doi.org/10.1074/jbc.M506162200)

Pitche PT 2005 [Pellagra]. Sante 15 205-208.

Pittelli M, Formentini L, Faraco G, Lapucci A, Rapizzi E, Cialdai F, Romano G, Moneti G, Moroni F \& Chiarugi A 2010 Inhibition of nicotinamide phosphoribosyltransferase: cellular bioenergetics reveals a mitochondrial insensitive NAD pool. Journal of Biological Chemistry 285 34106-34114. (https://doi.org/10.1074/jbc. M110.136739)

Preiss J \& Handler P 1958 Biosynthesis of diphosphopyridine nucleotide: I. Identification of intermediates. Journal of Biological Chemistry 233 488-492.

Preyat N, Rossi M, Kers J, Chen L, Bertin J, Gough PJ, Le Moine A, Rongvaux A, Van Gool F \& Leo O 2016 Intracellular nicotinamide adenine dinucleotide promotes TNF-induced necroptosis in a sirtuindependent manner. Cell Death and Differentiation 23 29-40. (https:// doi.org/10.1038/cdd.2015.60)

Purushotham A, Xu Q \& Li X 2012 Systemic SIRT1 insufficiency results in disruption of energy homeostasis and steroid hormone metabolism upon high-fat-diet feeding. FASEB Journal 26 656-667. (https://doi.org/10.1096/fj.11-195172)

Rajman L, Chwalek K \& Sinclair DA 2018 Therapeutic potential of NADBoosting molecules: the in vivo evidence. Cell Metabolism 27 529-547. (https://doi.org/10.1016/j.cmet.2018.02.011)

Ratajczak J, Joffraud M, Trammell SA, Ras R, Canela N, Boutant M, Kulkarni SS, Rodrigues M, Redpath P, Migaud ME, et al. 2016 NRK1 controls nicotinamide mononucleotide and nicotinamide riboside metabolism in mammalian cells. Nature Communications 713103. (https://doi.org/10.1038/ncomms13103)

Revollo JR, Korner A, Mills KF, Satoh A, Wang T, Garten A, Dasgupta B, Sasaki Y, Wolberger C, Townsend RR, et al. 2007 Nampt/PBEF/ Visfatin regulates insulin secretion in beta cells as a systemic NAD biosynthetic enzyme. Cell Metabolism 6 363-375. (https://doi. org/10.1016/j.cmet.2007.09.003)

Rodgers JT \& Puigserver P 2007 Fasting-dependent glucose and lipid metabolic response through hepatic sirtuin 1. PNAS 104 12861-12866. (https://doi.org/10.1073/pnas.0702509104)

Rodgers JT, Lerin C, Haas W, Gygi SP, Spiegelman BM \& Puigserver P 2005 Nutrient control of glucose homeostasis through a complex of PGC-1[alpha] and SIRT1. Nature 434 113-118. (https://doi. org/10.1038/nature03354)

Samal B, Sun Y, Stearns G, Xie C, Suggs S \& McNiece I 1994 Cloning and characterization of the cDNA encoding a novel human pre-Bcell colony-enhancing factor. Molecular and Cellular Biology $\mathbf{1 4}$ 1431-1437. (https://doi.org/10.1128/MCB.14.2.1431)

Sasaki Y, Araki T \& Milbrandt J 2006 Stimulation of nicotinamide adenine dinucleotide biosynthetic pathways delays axonal degeneration after axotomy. Journal of Neuroscience 26 8484-8491. (https://doi.org/10.1523/JNEUROSCI.2320-06.2006)

Schuster S, Penke M, Gorski T, Gebhardt R, Weiss TS, Kiess W \& Garten A 2015 FK866-induced NAMPT inhibition activates AMPK and downregulates mTOR signaling in hepatocarcinoma cells. Biochemical and Biophysical Research Communications 458 334-340. (https://doi.org/10.1016/j.bbrc.2015.01.111)

Shi W, Hegeman MA, van Dartel DAM, Tang J, Suarez M, Swarts H, van der Hee B, Arola L \& Keijer J 2017 Effects of a wide range of dietary nicotinamide riboside (NR) concentrations on metabolic flexibility and white adipose tissue (WAT) of mice fed a mildly obesogenic diet. Molecular Nutrition and Food Research 61 1600878. (https://doi. org/10.1002/mnfr.201600878)

Stein LR \& Imai S-I 2014 Specific ablation of Nampt in adult neural stem cells recapitulates their functional defects during aging. $E M B O$ Journal 33 1321-1340. (https://doi.org/10.15252/embj.201488740)

Stromsdorfer KL, Yamaguchi S, Yoon MJ, Moseley AC, Franczyk MP, Kelly SC, Qi N, Imai S \& Yoshino J 2016 NAMPT-mediated NAD(+) biosynthesis in adipocytes regulates adipose tissue function and multi-organ insulin sensitivity in mice. Cell Reports 16 1851-1860. (https://doi.org/10.1016/j.celrep.2016.07.027)

Tan B, Young DA, Lu Z-H, Wang T, Meier TI, Shepard RL, Roth K, Zhai Y, Huss K, Kuo M-S, et al. 2013 Pharmacological inhibition of nicotinamide phosphoribosyltransferase (NAMPT), an enzyme

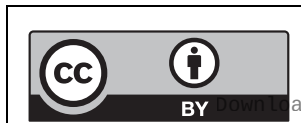

This work is licensed under a Creative Commons Attribution 4.0 Unported License. Aed from Bioscientifica com at 04/26/2023 06:25:36AM 
essential for NAD+ biosynthesis, in human cancer cells: metabolic basis and potential clinical implications. Journal of Biological Chemistry 288 3500-3511. (https://doi.org/10.1074/jbc. M112.394510)

Tan B, Dong S, Shepard RL, Kays L, Roth KD, Geeganage S, Kuo MS \& Zhao G 2015 Inhibition of nicotinamide phosphoribosyltransferase (NAMPT), an enzyme essential for NAD+ biosynthesis, leads to altered carbohydrate metabolism in cancer cells. Journal of Biological Chemistry 290 15812-15824. (https://doi.org/10.1074/jbc. M114.632141)

Taskinen MR \& Nikkila EA 1988 Effects of acipimox on serum lipids, lipoproteins and lipolytic enzymes in hypertriglyceridemia. Atherosclerosis 69 249-255. (https://doi.org/10.1016/00219150(88)90021-4)

Tedeschi PM, Bansal N, Kerrigan JE, Abali EE, Scotto KW \& Bertino JR 2016 NAD+ kinase as a therapeutic target in cancer. Clinical Cancer Research 22 5189-5195. (https://doi.org/10.1158/1078-0432.CCR-161129)

Tempel W, Rabeh WM, Bogan KL, Belenky P, Wojcik M, Seidle HF, Nedyalkova L, Yang T, Sauve AA, Park H-W, et al. 2007 Nicotinamide riboside kinase structures reveal new pathways to NAD+. PLoS Biology 5 e263. (https://doi.org/10.1371/journal.pbio.0050263)

To C, Kim EH, Royce DB, Williams CR, Collins RM, Risingsong R, Sporn MB \& Liby KT 2014 The PARP inhibitors, veliparib and olaparib, are effective chemopreventive agents for delaying mammary tumor development in BRCA1-deficient mice. Cancer Prevention Research 7 698-707. (https://doi.org/10.1158/1940-6207. CAPR-14-0047)

Trammell SA, Schmidt MS, Weidemann BJ, Redpath P, Jaksch F, Dellinger RW, Li Z, Abel ED, Migaud ME \& Brenner C $2016 a$ Nicotinamide riboside is uniquely and orally bioavailable in mice and humans. Nature Communications 7 12948. (https://doi. org/10.1038/ncomms12948)

Trammell SA, Weidemann BJ, Chadda A, Yorek MS, Holmes A, Coppey LJ, Obrosov A, Kardon RH, Yorek MA \& Brenner C $2016 b$ Nicotinamide riboside opposes type 2 diabetes and neuropathy in mice. Scientific Reports 6 26933. (https://doi.org/10.1038/srep26933)

Uddin GM, Youngson NA, Sinclair DA \& Morris MJ 2016 Head to head comparison of short-term treatment with the $\mathrm{NAD}(+)$ precursor nicotinamide mononucleotide (NMN) and 6 weeks of exercise in obese female mice. Frontiers in Pharmacology 7 258. (https://doi. org/10.3389/fphar.2016.00258)

van de Weijer T, Phielix E, Bilet L, Williams EG, Ropelle ER, Bierwagen A, Livingstone R, Nowotny P, Sparks LM, Paglialunga S, et al. 2015 Evidence for a direct effect of the NAD+ precursor acipimox on muscle mitochondrial function in humans. Diabetes 64 1193-1201. (https://doi.org/10.2337/db14-0667)

Van Gool F, Galli M, Gueydan C, Kruys V, Prevot PP, Bedalov A, Mostoslavsky R, Alt FW, De Smedt T \& Leo O 2009 Intracellular NAD levels regulate tumor necrosis factor protein synthesis in a sirtuin-dependent manner. Nature Medicine 15 206-210. (https://doi. org/10.1038/nm.1906)

VanLinden MR, Dölle C, Pettersen IKN, Kulikova VA, Niere M, Agrimi G, Dyrstad SE, Palmieri F, Nikiforov AA, Tronstad KJ, et al. 2015 Subcellular distribution of NAD+ between cytosol and mitochondria determines the metabolic profile of human cells. Journal of Biological Chemistry 290 27644-27659. (https://doi.org/10.1074/jbc. M115.654129)
Veech RL, Guynn R \& Veloso D 1972 The time-course of the effects of ethanol on the redox and phosphorylation states of rat liver. Biochemical Journal 127 387-397. (https://doi.org/10.1042/ bj1270387)

Walsh CT, Tu BP \& Tang Y 2018 Eight kinetically stable but thermodynamically activated molecules that power cell metabolism. Chemical Reviews 118 1460-1494. (https://doi.org/10.1021/acs. chemrev.7b00510)

Wang T, Zhang X, Bheda P, Revollo JR, Imai S \& Wolberger C 2006 Structure of Nampt/PBEF/visfatin, a mammalian NAD+ biosynthetic enzyme. Nature Structural and Molecular Biology 13 661-662. (https:// doi.org/10.1038/nsmb1114)

Wang X, Hu X, Yang Y, Takata T \& Sakurai T 2016 Nicotinamide mononucleotide protects against beta-amyloid oligomer-induced cognitive impairment and neuronal death. Brain Research 1643 1-9. (https://doi.org/10.1016/j.brainres.2016.04.060)

Warburg O \& Christian W 1936 Pyridine, the hydrogen transfusing component of fermentative enzymes. Helvetica Chimica Acta 19 79-88. (https://doi.org/10.1002/hlca.193601901199)

Xu F, Gao Z, Zhang J, Rivera CA, Yin J, Weng J \& Ye J 2010 Lack of SIRT1 (Mammalian Sirtuin 1) activity leads to liver steatosis in the SIRT1+/- mice: a role of lipid mobilization and inflammation. Endocrinology 151 2504-2514. (https://doi.org/10.1210/en.2009-1013)

Xu W, Barrientos T, Mao L, Rockman HA, Sauve AA \& Andrews NC 2015 Lethal cardiomyopathy in mice lacking transferrin receptor in the heart. Cell Reports 13 533-545. (https://doi.org/10.1016/j. celrep.2015.09.023)

Yamamoto T, Byun J, Zhai P, Ikeda Y, Oka S \& Sadoshima J 2014 Nicotinamide mononucleotide, an intermediate of NAD+ synthesis, protects the heart from ischemia and reperfusion. PLOS ONE 9 e98972. (https://doi.org/10.1371/journal.pone.0098972)

Yang H, Yang T, Baur JA, Perez E, Matsui T, Carmona JJ, Lamming DW, Souza-Pinto NC, Bohr VA, Rosenzweig A, et al. 2007 Nutrientsensitive mitochondrial NAD+ levels dictate cell survival. Cell 130 1095-1107. (https://doi.org/10.1016/j.cell.2007.07.035)

Yoon MJ, Yoshida M, Johnson S, Takikawa A, Usui I, Tobe K, Nakagawa T, Yoshino J \& Imai S 2015 SIRT1-mediated eNAMPT secretion from adipose tissue regulates hypothalamic NAD+ and function in mice. Cell Metabolism 21 706-717. (https://doi. org/10.1016/j.cmet.2015.04.002)

Yoshino J, Mills KF, Yoon MJ \& Imai S 2011 Nicotinamide mononucleotide, a key $\mathrm{NAD}(+)$ intermediate, treats the pathophysiology of diet- and age-induced diabetes in mice. Cell Metabolism 14 528-536. (https://doi.org/10.1016/j.cmet.2011.08.014)

Zhang H, Ryu D, Wu Y, Gariani K, Wang X, Luan P, D'Amico D, Ropelle ER, Lutolf MP, Aebersold R, et al. $2016 \mathrm{NAD}^{+}$repletion improves mitochondrial and stem cell function and enhances life span in mice. Science 352 1436-1443. (https://doi.org/10.1126/ science.aaf2693)

Zhang LQ, Van Haandel L, Xiong M, Huang P, Heruth DP, Bi C, Gaedigk R, Jiang X, Li DY, Wyckoff G, et al. 2017 Metabolic and molecular insights into an essential role of nicotinamide phosphoribosyltransferase. Cell Death and Disease 8 e2705. (https:// doi.org/10.1038/cddis.2017.132)

Zhou CC, Yang X, Hua X, Liu J, Fan MB, Li GQ, Song J, Xu TY, Li ZY, Guan YF, et al. 2016 Hepatic NAD(+) deficiency as a therapeutic target for non-alcoholic fatty liver disease in ageing. British Journal of Pharmacology 173 2352-2368. (https://doi.org/10.1111/bph.13513)
Received in final form 21 May 2018

Accepted 30 May 2018

Accepted Preprint published online 30 May 2018 http://jme.endocrinology-journals.org https://doi.org/10.1530/JME-18-0085
(C) 2018 The authors Published by Bioscientifica Ltd. Printed in Great Britain

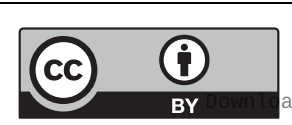

This work is licensed under a Creative Common Attribution 4.0 Unported License.

ded from Bioscientifica.com at 04/26/2023 06:25:36AM 